\title{
Are you attracted? Do you remain? Meta-analytic evidence on flexible work practices
}

\author{
Greta Onken-Menke $^{1} \cdot$ Stephan Nüesch $^{1}$. \\ Claudia Kröll ${ }^{1}$
}

Received: 30 January 2017/ Accepted: 24 November 2017/Published online: 7 December 2017

(C) The Author(s) 2017. This article is an open access publication

\begin{abstract}
This meta-analysis investigates how three flexible work practices (FWPs), flexible work schedules, telecommuting and sabbaticals, affect organizational attractiveness for job seekers and the organizational attachment of employees. Based on organizational support theory and signalling theory, we conjecture that anticipated organizational support mediates the positive relationship between FWPs and organizational attractiveness. Applying the conservation of resources theory, we suggest that FWPs increase organizational attachment through increased perceived autonomy. Meta-analytic results based on 68 studies and 52,738 employees indicate that FWPs increase organizational attractiveness and that the positive effects are partially mediated by anticipated organizational support. We also find that flexible work schedules and sabbaticals (but not telecommuting) increase organizational commitment and that all FWPs decrease turnover intention. Furthermore, these effects are partially mediated by perceived autonomy. Implications for practice and future research are discussed.
\end{abstract}

Keywords Flexible work schedules - Telecommuting - Sabbaticals · Organizational attractiveness - Organizational attachment

\section{Introduction}

As an organization's competitive advantage is often based on specific knowledge of its employees (Campbell et al. 2012), it is crucial for organizations to attract and retain the most talented employees. To be considered as a desirable employer, both externally to potential new hires and internally to existing employees, more and

Stephan Nüesch

nueesch@wwu.de

1 University of Münster, Georgskommende 26, 48143 Münster, Germany 
more organizations strategically manage their human capital in times of talent shortage (e.g. Dineen and Allen 2016). Organizations increasingly offer flexible work practices (FWPs), like flexible work schedules, telecommuting and sabbaticals, to attract job seekers (e.g. Thompson et al. 2015) and retain existing employees (e.g. Casper and Harris 2008), who increasingly place importance on FWPs. For example, $75 \%$ of employees and $74 \%$ of job seekers state that they value FWPs most over other benefits offered by employees (CareerArc 2015). While in practice the majority of companies offer FWPs (Society for Human Resource Management 2017), empirical studies examining the effect of FWPs on organizational attractiveness and organizational attachment have produced conflicting results. Some studies have found that FWPs increase organizational attractiveness (e.g. Thompson et al. 2015) and organizational attachment (e.g. Roehling et al. 2001). Other studies, however, have found no relationship between FWPs and organizational attractiveness (e.g. Kausel and Slaughter 2011) or between FWPs and organizational attachment (e.g. Haar 2008; Behson 2005), or have even found that FWPs decrease organizational attachment (e.g. Masuda et al. 2012). Hence, a meta-analytic summary is important to provide clear insights on the links between FWPs and organizational attractiveness and organizational attachment, respectively.

Through conducting a meta-analysis, we quantitatively summarize the findings of primary studies and compute overall estimates of the effects of FWPs on the organizational attractiveness both for job seekers and for existing employees. More specifically, we test whether and how FWPs increase job seekers' organizational attractiveness and employees' organizational attachment.

We analyse the effects of three different FWPs, namely flexible work schedules, telecommuting, and sabbaticals, on organizational attractiveness and organizational attachment, the latter operationalized by organizational commitment and turnover intention. Furthermore, we investigate how FWPs and the outcomes are related by integrating two different mediators into the model. Drawing on signalling theory (Spence 1973), organizational support theory (Eisenberger et al. 1986) and prior empirical research (e.g. Casper and Buffardi 2004; Thompson et al. 2015), we argue that the link between FWPs and organizational attractiveness to job seekers is mediated by the job seekers' anticipated organizational support and that the link between FWPs and employees' organizational attachment is mediated by employees' perceived autonomy. Anticipated organizational support is defined as the job seekers' anticipation of the extent to which the organization will value their contribution and care about their wellbeing (Eisenberger et al. 1986), while perceived autonomy describes the employees' perception of the extent to which they can structure and control how, when and where they work (Gajendran and Harrison 2007). In addition, we examine the quality of primary study and the availability versus use of FWPs as potential moderators, because these factors are likely to cause heterogeneity across the primary studies and effect sizes.

We make four contributions to the literature. First, unlike prior meta-analyses (e.g. Butts et al. 2013), we analyse the specific effects of flexible work schedules, telecommuting and sabbaticals rather than a joint effect of a bundle of FWPs. FWPs reflect different terms of flexibility regarding when (e.g. flexible work schedules), where (e.g. telecommuting), and for how long work is conducted (Hill et al. 2008), 
whereby the latter includes decisions about breaks from work (e.g. sabbaticals). Thus, the individual FWPs are not interchangeable and aggregating them into a single construct may hide differential effects (Allen et al. 2013). In doing so, we contribute to the literature by responding to a call for more research on the effects of individual FWPs (Kossek et al. 2010; Allen et al. 2013).

Second, this analysis takes a closer look at the underlying psychological mechanisms of the effects. Therefore, we develop and test a model of the indirect effects of FWPs on organizational attractiveness and organizational attachment, respectively. Prior analyses of mediators in the relationships of FWPs with organizational attractiveness and with organizational attachment often concentrate on family issues like work-family conflict (e.g. McNall et al. 2009; Ivanauskaite 2015). However, there are likely to be other mediating factors concerning personal perception besides family.

Third, to the authors' knowledge, this is the first meta-analysis that links two research streams that have mostly been examined separately, namely the effects on both the external (organizational attractiveness) and internal (organizational attachment) perspectives of an employer image. A separation of the two different samples might make sense in the data collection process of prior studies, but it inhibits discussions about FWPs from different perspectives. Thus, this paper gives some insights into the effectiveness of FWPs as an attracting and a retaining strategy.

Fourth, this is the first meta-analysis that includes sabbaticals as a predictor of organizational attractiveness and attachment. Because sabbaticals are increasingly offered by employees (Society for Human Resource Management 2016), knowing their effect is highly relevant for practitioners.

\section{Research on FWPs}

We distinguish between three different FWPs, which relate to different kinds of flexibility, namely when (e.g. flexible work schedules), where (e.g. telecommuting), and for how long work is conducted (Hill et al. 2008), whereby the latter includes decisions about breaks from work (e.g. sabbaticals). Thereby, flexible work schedules allow employees to control their scheduling of working hours (Baltes et al. 1999), telecommuting enables employees to decide where and often also when they work (Gajendran and Harrison 2007) and sabbaticals give employees flexibility to take extended periods of time away from work without losing their legal rights as employees (Carr and Tang 2005). In this meta-analysis, sabbaticals are defined as paid leaves (e.g. Kang 2013). This definition of sabbaticals differs from some in the literature, where sabbaticals can also refer to unpaid breaks (Carr and Tang 2005). As it is shown in the individual definitions of the FWPs, flexibility in the term FWPs here refers to extending the decision rights for employees.

We focus our analyses on flexible work schedules, telecommuting, and sabbaticals. Flexible work schedules and telecommuting are the most widely implemented FWPs (Leslie et al. 2012). We additionally analyse the effects of sabbaticals because sabbaticals are also increasingly offered by organizations and 
unlike flexible work schedules and telecommuting, sabbaticals do not refer to flexibility in daily work routines (Society for Human Resource Management 2015; Bal and de Lange 2015).

\subsection{The effects of FWPs on external outcomes}

Job seekers are typically imperfectly informed about a hiring organization (Rynes and Miller 1983). According to the signalling theory (Spence 1973), job seekers interpret observable characteristics of the organization as indicators for nonobservable information. Thus, information received during the recruitment process may influence their perception of the organization (Casper and Buffardi 2004). According to the organizational support theory (Eisenberger et al. 1986), we assume that individuals form expectations about how much the organization values them and cares about their wellbeing. Job seekers form their expectations based on, for example, organizational recruitment activities and recruiter communication (Cable et al. 2000). The meta-analysis by Rhoades and Eisenberger (2002) also showed that working conditions are related to perceived organizational support. Information about the offer of FWPs fuels expectations that such organizations are supportive of employees' personal needs (Grover and Crooker 1995). We, therefore, argue that offering flexible work schedules, telecommuting and sabbaticals increases prospective employees" anticipated organizational support (AOS), and as a consequence increases organizational attractiveness in the job market. Hence, we assume that the positive relationship between FWPs and organizational attractiveness is mediated by anticipated organizational support.

Hypothesis 1: (H1a) Flexible work schedules, (H1b) telecommuting and (H1c) sabbaticals are positively related to anticipated organizational support.

Hypothesis 2: (H2a) Flexible work schedules, (H2b) telecommuting and (H2c) sabbaticals are positively related to organizational attractiveness.

Hypothesis 3: Anticipated organizational support mediates the relationship between FWPs (flexible work schedules, telecommuting, sabbaticals) and organizational attractiveness.

\subsection{The effects of FWPs on internal outcomes}

By being involved in the daily work routines, employees are better informed about organizational characteristics than job seekers. Employees not only learn whether FWPs are offered or not but also experience how easy or difficult it is to make use of FWPs and whether FWPs really help them to balance their work and non-work demands.

We use the conservation of resources (COR) theory to explain the effects of FWPs on organizational attachment. The COR theory (Hobfoll 1989) explains that people are motivated to obtain, retain, foster and protect their resources. Resources include objects, personal characteristics and conditions that people value. When resources are endangered or even lost or cannot be restocked, people experience 
stress. Thereby, resource loss is assumed to occur when the demands of one domain drain the resources needed to meet the demands of another domain (Grandey and Cropanzano 1999).

One likely approach to enable the employees to protect their resources is to increase the perceived autonomy (Hall et al. 2006). Perceived autonomy increases aspects like self-efficacy, self-esteem and senses of optimism and mastery and increases personal resilience in stressful work circumstances (Hobfoll 2002). FWPs increase perceived autonomy by giving employees more control over how, when and where they work (e.g. Baltes et al. 1999). Flexible work schedules, for example, increase the perceived autonomy of employees because they can themselves decide when they work. Telecommuting gives employees more control over the work environment, such as lighting and temperature. When taking a sabbatical, employees usually have a high autonomy in determining its content, location and timing. Based on the COR theory, sabbaticals allow the acquisition of other kind of resources like improved vigor (Hobfoll 1989; Zahorski 1994), which can be reallocated to private activities, projects or family needs (Guimaraes and Dallow 1999; Duxbury et al. 1998). Reallocated resources increase job and life fulfillment (Bailey and Kurland 2002), which increases stress resistance capacity (Hobfoll 1989). Perceived autonomy generally helps to protect valuable resources such as time and energy (Hall et al. 2006). Overall, offering FWPs increases employees“ perceived autonomy. A higher level of perceived autonomy is in turn expected to increase employees ' organizational attachment, because it helps to protect valuable resources such as time and energy (Hall et al. 2006). Therefore, we argue that the positive relationship between FWPs and organizational attachment is mediated by perceived autonomy.

Hypothesis 4: (H4a) Flexible work schedules, (H4b) telecommuting and (H4c) sabbaticals are positively related to perceived autonomy.

Hypothesis 5: (H5a) Flexible work schedules, (H5b) telecommuting and (H5c) sabbaticals are positively related to organizational commitment and negatively related to turnover intention. ${ }^{1}$

Hypothesis 6: Perceived autonomy mediates the relationship between FWPs (flexible work schedules, telecommuting, sabbaticals) and organizational attachment (organizational commitment, turnover intention).

Figure 1 summarizes the prior hypothesized relationships of FWPs with external and internal outcomes.

\subsection{Differential effects of FWPs on external and internal outcomes}

The three major forms of FWPs are flexibility in terms of time (e.g. flexible work schedules), flexibility in terms of location (e.g. telecommuting) and flexibility in

Par20 If sabbaticals cause employees to reconsider their life including the current job, sabbaticals could also increase turnover intention. However, we argue that the COR arguments dominate and that sabbaticals decrease turnover intention. 
Fig. 1 Model linking FWPs to external and internal outcomes. $A O S$ anticipated organizational support

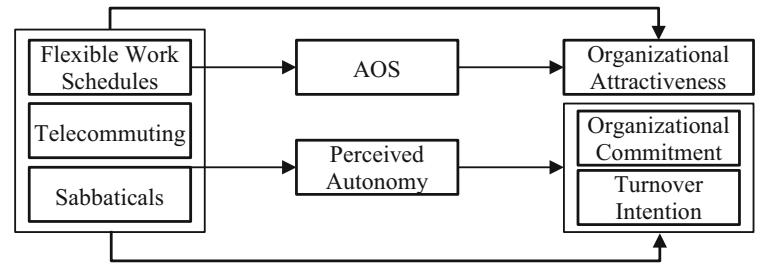

terms of periods away from work (e.g. sabbaticals) (Hill et al. 2008). These three categories in turn can be aggregated to two distinct dimensions of flexibility: irregular flexibility, which refers to irregular breaks from work, such as sabbaticals, and regular flexibility, which refers to flexibility in the daily work routine, such as flexible work schedules and telecommuting (Bal and de Lange 2015). As a consequence, unlike employees who use flexible work schedules and telecommuting, employees on a sabbatical do not have to continue working on a daily basis but take a longer period off while still receiving a (reduced) salary and social insurance contributions. Sabbaticals are, therefore, more useful in helping employees to disconnect from work (e.g. Davidson et al. 2010). Sabbaticals enable employees to conduct totally new projects, provide new and stimulating perspectives and thus improve vigor (Zahorski 1994).

In addition, sabbaticals are still rarely offered while flexible work schedules and telecommuting are more commonly offered (Society for Human Resource Management 2015). In 2016, only 5\% of the U.S. firms offered sabbaticals in 2016 (Society for Human Resource Management 2017). The opportunity of taking a sabbatical may, therefore, be perceived as a special privilege, which should increase both organizational attractiveness and organizational attachment. Flexible work schedules and telecommuting are more likely to be taken for granted than sabbaticals. Hence, we assume that sabbaticals have a stronger impact on organizational attractiveness and attachment than flexible work schedules and telecommuting.

Hypothesis 7: Sabbaticals have a stronger effect on $(\mathrm{H} 7 \mathrm{a})$ organizational attractiveness and $(\mathrm{H} 7 \mathrm{~b})$ organizational attachment than flexible work schedules and telecommuting.

\subsection{Moderator relationships}

In addition to the hypothesized effects of FWPs, we assume that moderators might temper or strengthen the effects of FWPs on particular outcomes. An examination of the relevant literature motivates us to consider the following two moderators: availability versus use of FWPs (e.g. Allen et al. 2013) and the quality of the primary studies (e.g. Baltes et al. 1999). When referring to availability of FWPs, it is meant that in the primary studies the individuals were asked if FWPs were offered, but we have no information about their usage. We propose that some employees might use them and some might not. In the existing literature, there are arguments that the availability versus use of FWPs relates to different sizes of the effects (e.g. 
Butts et al. 2013). On the one hand, the availability of FWPs gives employees only a sense of control (Kossek et al. 2006), whereas the use of FWPs actually provides the employees an internal locus of control and hence autonomy (Allen et al. 2013) as well as organizational attachment (Kossek et al. 2006). On the other hand, researchers argue that the availability of FWPs already symbolizes appreciation and support and thus increases organizational attractiveness and attachment (e.g. Grover and Crooker 1995; Batt and Valcour 2003). Grover and Crooker (1995) found that individuals who personally benefited from FWPs, the users, professed no higher attachment to the organization than individuals who chose not to use the offered FWPs. Moreover, experience of the downsides of FWPs that go unrecognized by non-users (Golden and Veiga 2008; Rau and Hyland 2002) might decrease the effect sizes for users. We, therefore, assume that the effect sizes are stronger when FWPs are simply available than when FWPs are actually used.

Hypothesis 8: The relationships of FWPs with anticipated organizational support (H8a), organizational attractiveness (H8b), perceived autonomy (H8c) and organizational attachment (H8d) are stronger in the case of availability of FWPs compared to use of FWPs.

In addition, we control for the quality of primary studies as it may influence the reported effect sizes (e.g. Baltes et al. 1999). Publication bias suggests that not only the study quality but also the size and statistical significance of the effects increase the likelihood of being published (Rosenthal 1979). Using both published and unpublished primary studies, we therefore argue that the effect sizes of the highquality primary studies will be higher than the effect sizes of the low-quality primary studies.

Hypothesis 9: The relationships of FWPs with anticipated organizational support (H9a), organizational attractiveness (H9b), perceived autonomy (H9c) and organizational attachment (H9d) are strengthened by the quality of the primary studies.

\section{Method}

\subsection{Literature search and inclusion criteria}

We conducted a search for relevant literature in the databases JSTOR, PsycINFO and EBSCO using the English keywords flexible work schedule, flextime, flexitime, flexible scheduling, telecommuting, telework, remote work, work at home, virtual work, flexplace, home office, sabbaticals, paid time offs, and paid leaves. We additionally use the German translations of the keywords to also consider primary studies written in German. The aim of a meta-analysis is to quantitatively summarize all the available empirical results for the respective relationships. This also includes unpublished studies. Otherwise, the problem of a publication bias may occur, since significant findings are more likely to be published than insignificant findings, which can lead to overestimated results (Rosenthal 1979). Thus, different 


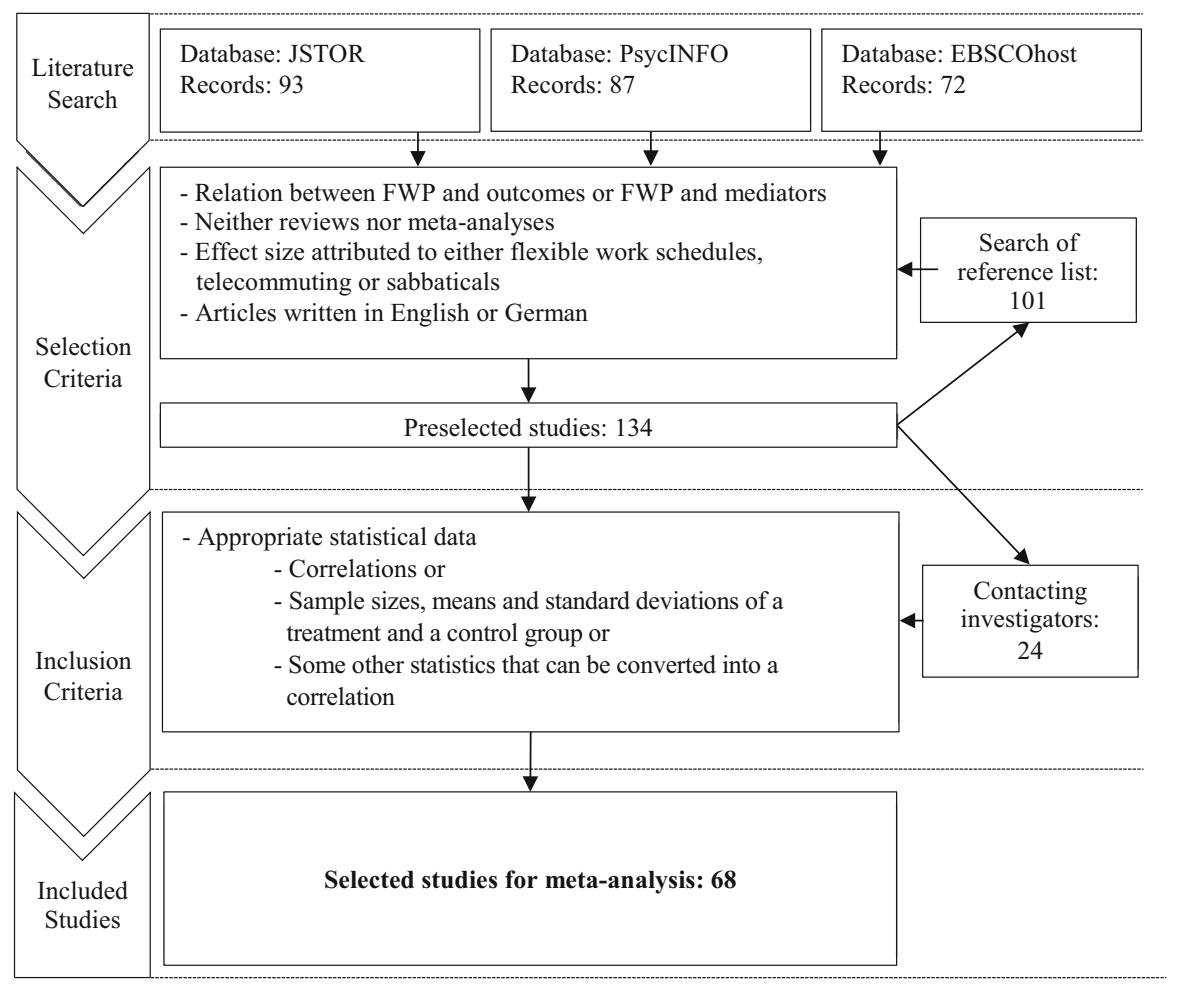

Fig. 2 Schematic diagram of literature research and inclusion

types of literature were included, specifically papers, master theses, doctoral theses, working papers and conference papers. To further identify unpublished studies, we checked http://scholar.google.com and conference programs of the Academy of Management conference, the Society of Industrial and Organizational Psychology, and the Southern Management Association. The reference lists of included studies were screened for additional related studies. If a study met the inclusion criteria but did not report the necessary statistical data or only reported bundles of FWPs, we contacted the investigator(s). Through this process, we identified 134 potentially relevant studies.

Figure 2 shows an overview of the literature search and inclusion criteria. To be included in this analysis, a study had to: (a) examine the relationship between at least one FWP and one outcome or on one of the mediators; (b) clearly assign the effect size to one of the three categories of FWPs; (c) be written in English or German; and (d) allow the statistical analysis by reporting either correlations or statistics that could be converted into correlations (e.g. $F$ test). Following the application of these inclusion criteria, 68 studies with 74 separate samples and 122 relationships were included in our meta-analysis. Of these studies 55 were published and 13 unpublished. 


\subsection{Coding}

Our coding guide was based on the procedure of Lipsey and Wilson (2001). To evaluate the coding decisions, two of the study authors independently coded each study. For this purpose, the two authors were provided with a standardized coding guide. After they had tested the procedure and the coding guide on example studies, problems were discussed and conventions were defined. The interrater agreement rate (cf., Orwin and Vevea 2009) was 98\%. Thus, the reliability of the coding scheme can be judged as satisfying.

\subsubsection{Predictors}

We included the three different FWPs, namely flexible work schedules, telecommuting and sabbaticals in our study. These FWPs were measured by self-report and were treated as exhibiting perfect reliability (e.g. Butts et al. 2013). While we used the specific measures of each of these FWPs to test their direct effects, we were compelled to form an aggregate latent measure of FWPs to test the mediation hypotheses as this was the only way to satisfy the minimum requirement of five observations per estimated parameter in the structural equation models (Bentler and Chou (1987).

\subsubsection{Mediators and outcome variables}

In coding the mediators and outcome variables, we followed widely accepted definitions and their construct-label synonyms. The mediators included anticipated organizational support and perceived autonomy (task autonomy, job autonomy).

We collected effect sizes for both external and internal outcomes. The external outcome organizational attractiveness (applicant attraction) is defined as the extent to which a job seeker desires to work for a specific organization (Highhouse et al. 2003). The internal outcomes include organizational commitment, which evaluates an employee's desire to remain with the organization (Mowday et al. 1979), and turnover intention (intention to quit, intention to stay, the latter was reversely coded), which measures an employee's readiness to leave the organization (Bothma and Roodt 2013). While we used the specific measures of organizational commitment and turnover intention to test their direct effects, we formed an aggregate latent measure of organizational attachment with turnover intention (reversely coded) to test the mediation and comparison hypotheses. This is in line with other meta-analyses (e.g. Butts et al. 2013; Gajendran and Harrison 2007).

\subsubsection{Moderators}

We measured availability versus use of FWPs as moderator, coded as dichotomous variables $(0=$ availability, $1=$ use $)$. In addition, the quality of the primary studies was examined using two types of measures, the Study Design and Implementation Assessment Device (Study DIAD) by Valentine and Cooper (2008) and the Journal Impact Factor. Study DIAD judges quality in four categories, namely the fit between 
concepts and operations, the clarity of causal inference, the generality of findings, and the precision of outcome estimation. ${ }^{2}$ The rating measure is a weighted mean of the four areas with a value between 0 and 1 . The mean quality of the studies in our meta-analysis was 0.86 , indicating that in average a study met $86 \%$ of the Study DIAD requirements, which we consider as a good value. The more objective Journal Impact Factor has the disadvantage of excluding unpublished primary studies.

\subsection{Meta-analytic techniques and statistical adjustments}

We used the statistical freeware $\mathrm{R}$ ( $\mathrm{R}$ Core Team 2015) and in particular the package "metaSEM" (Cheung 2015) to conduct the statistical analyses. All statistical tests were two-sided with a significance level of 0.05 .

Because we assumed heterogeneity across FWPs and sample characteristics, the random effects model seemed appropriate (Viechtbauer 2010). This model expects the true effect sizes to have different values in different studies, and to be random but normally distributed, taking on different values in different studies (Raudenbush 2009). We investigated the validity of the assumption of a random effects model using the Chi-squared statistic $Q$. It indicates whether all the observed heterogeneity was due to sampling error variance. We first transformed reported statistics such as means and standard deviations, $F$ tests and standardized betas into correlations. As all betas were within the range from -0.50 and 0.50 , the transformation is appropriate (Peterson and Brown 2005). When studies reported multiple measurements referring to the same construct, the combined effect sizes were calculated using Hunter and Schmidt's (2004) formula.

Prior to calculating the estimated population effect size Fisher's $z$, its variance and confidence intervals (CIs), we disattenuated each effect correlation for the unreliability of the variables involved. For studies that did not report reliabilities, we imputed reliability from the sample-weighted mean reliability of other studies that involved the same variables (e.g. Hunter and Schmidt 2004). We only ran metaanalyses when we had at least three independent effect sizes (Hunter and Schmidt 2004).

\subsection{Model testing}

To test the mediating effects, we used meta-analytic structural equation modelling (MASEM) following Cheung and Chan (2005). To investigate the external and internal outcomes independently, we conducted two separate MASEMs, which are in the following referred to as external model and internal model.

Our external structural model used one latent construct to represent FWPs, while anticipated organizational support and organizational attractiveness were considered as single-item indicators without correction for measurement error, as these corrections were made through the meta-analysis. The internal structural model not

Par37 The Study DIAD approach might be subjective, but offers the possibility to calculate quality ratings for published and unpublished studies, which is very important to prevent the publication bias in the metaanalytic results. 
only used the latent construct of FWPs but also used a second latent construct to represent organizational attachment in place of the manifest indicators organizational commitment and turnover intention. Perceived autonomy was considered as single-item indicator without correction for measurement error, as these corrections were done through the meta-analysis. To build the two correlation matrices in MASEM, we combined corrected population correlation coefficients from the current study with previous meta-analytic results (e.g. Butts et al. 2013; Chang et al. 2009). As no prior meta-analysis had investigated the relationship between anticipated organizational support and organizational attractiveness, we used primary studies included in the current meta-analysis to estimate the effect size (e.g. Chang et al. 2009). To calculate the underlying sample sizes of the correlation matrices, we used the conservative harmonic mean of the sample sizes of the respective matrix (e.g. Stajkovic et al. 2009; Viswesvaran and Ones 1995), leading to $N=1159$ in the external model and $N=3363$ in the internal model.

\subsection{Moderator analyses}

We estimated the effects of the moderator study quality using weighted least square (WLS) regressions on the Fisher's $z$ transformed corrected correlations (Hedges and Olkin 1985), because this method is the most accurate one for continuous moderators in meta-analyses (Steel and Kammeyer-Mueller 2002). To test the moderator availability versus use of FWPs, we conducted subgroup analyses (Hedges and Olkin 1985).

\section{Results}

\subsection{Study characteristics}

Table 1 summarizes the measured predictors, the outcomes, whether the respective effect sizes of some statistical data had to be transformed into correlations, and the quality score of each primary study included in this meta-analysis. Table 1 also shows when the investigators of the primary study had to be contacted due to missing statistical data and when the reliability of an outcome was not available and, therefore, had to be imputed.

\subsection{Bivariate relationships}

The meta-analytic results for the direct effects of FWPs on external outcomes are presented in Table 2. Our data support Hypotheses $1 \mathrm{a}$ and $1 \mathrm{~b}$ by finding that flexible work schedules $(\rho=0.25,95 \% \mathrm{CI}=0.09,0.42)$ and telecommuting $(\rho=0.22$, $95 \% \mathrm{CI}=0.06,0.37$ ) are positively related to anticipated organizational support. Hypothesis 1c could not be tested, as only two primary studies analyse the relationship between sabbaticals and anticipated organizational support. As the $Q$ tests of heterogeneity are significant for flexible work schedules $(p<0.001)$ and telecommuting $(p<0.01)$, the assumption of a random effects model is appropriate. 


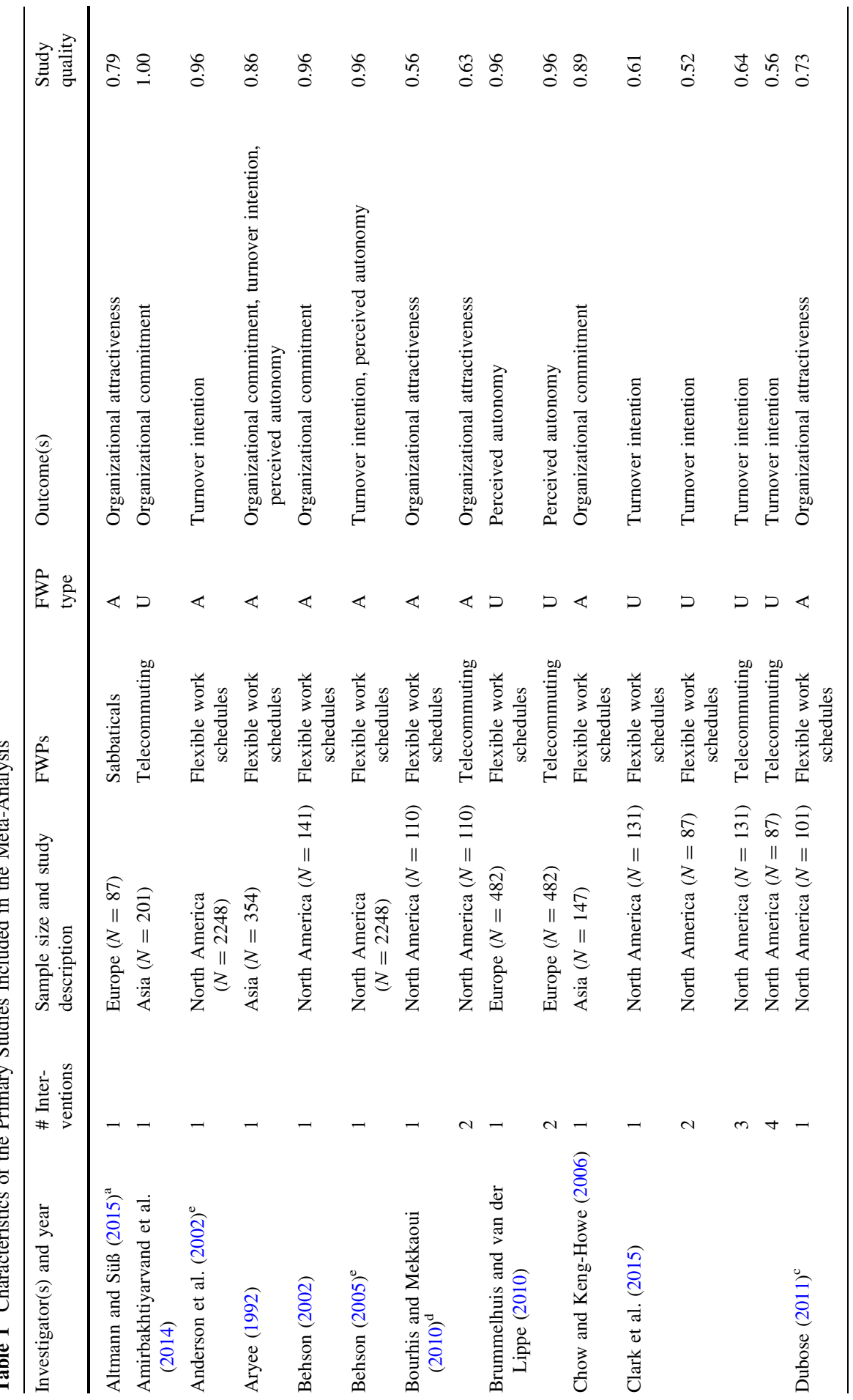









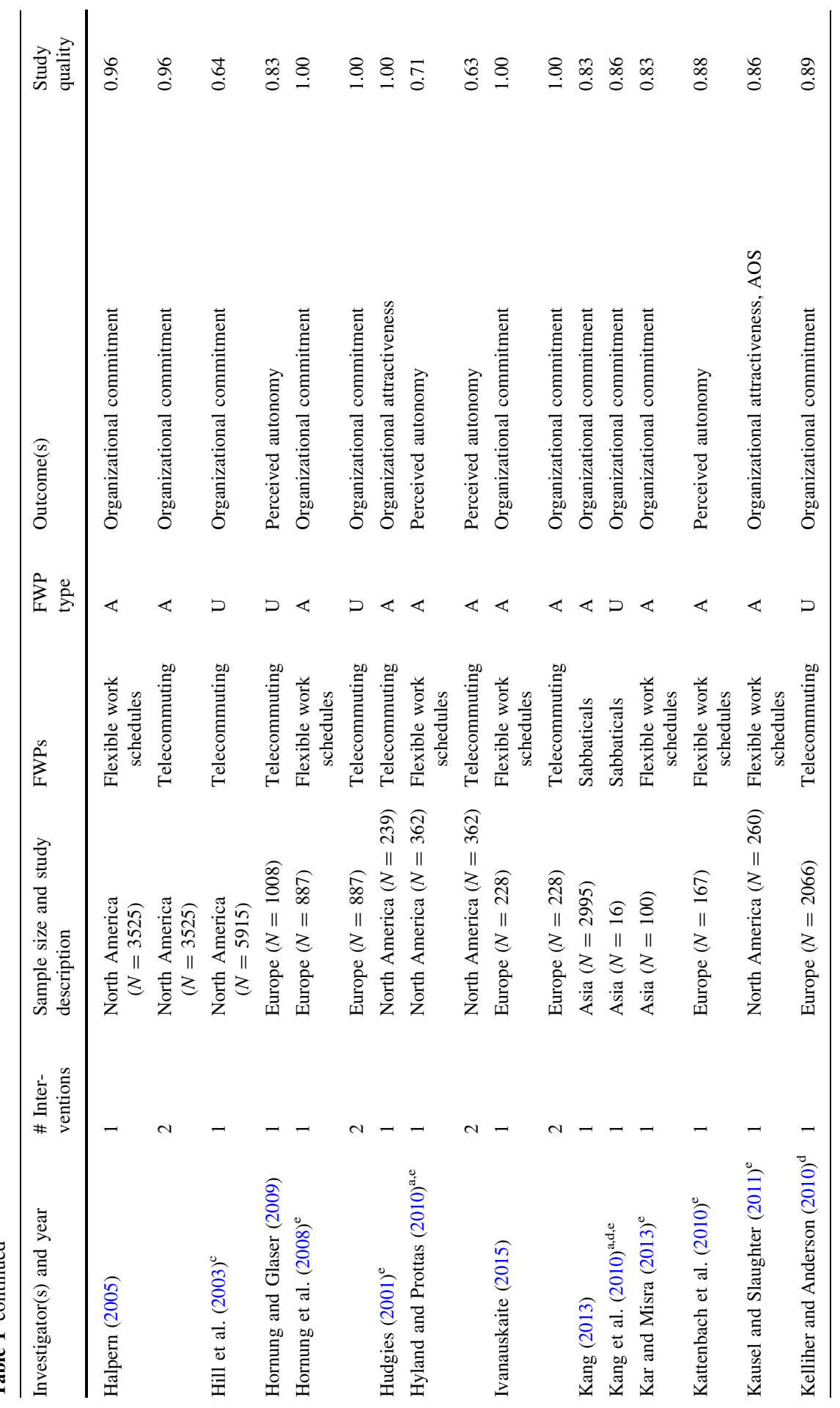














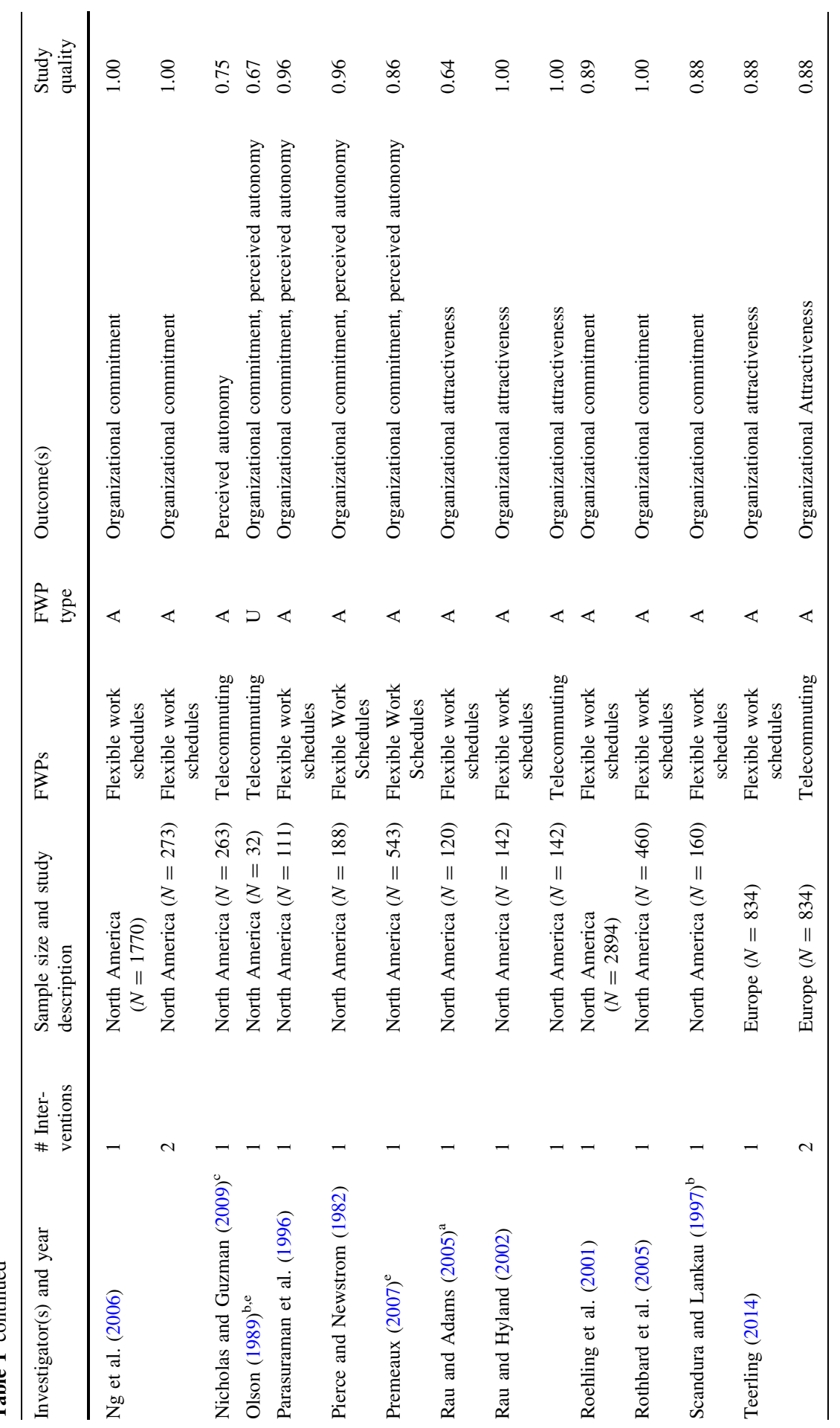




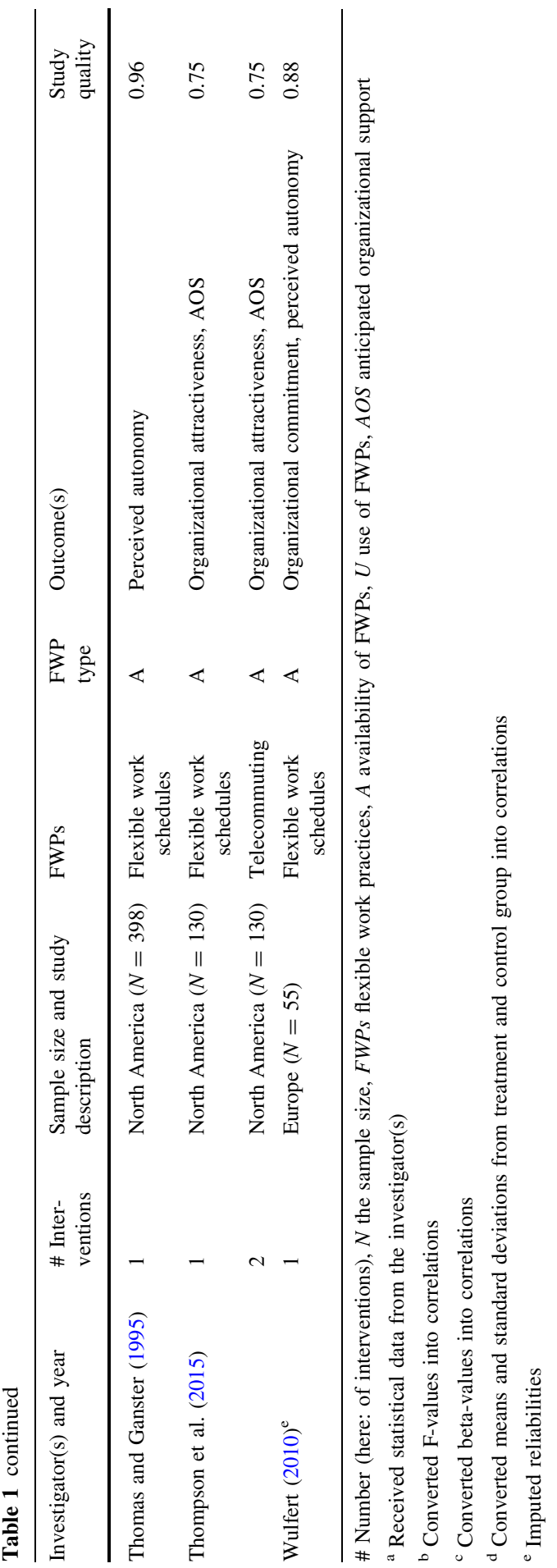


Table 2 Meta-analytic results for bivariate relationships between FWPs, mediators and external outcome variables

\begin{tabular}{|c|c|c|c|c|c|c|c|c|}
\hline \multirow[t]{2}{*}{ Relationship } & \multirow[t]{2}{*}{$K$} & \multirow[t]{2}{*}{$N$} & \multirow[t]{2}{*}{$r$} & \multirow[t]{2}{*}{$\rho$} & \multirow{2}{*}{$\begin{array}{l}\text { SD } \\
\rho\end{array}$} & \multirow{2}{*}{$\begin{array}{l}\% \\
\text { SE }\end{array}$} & $95 \% \mathrm{CI}$ & \multirow[t]{2}{*}{$Q$} \\
\hline & & & & & & & LL & \\
\hline
\end{tabular}

\begin{tabular}{|c|c|c|c|c|c|c|c|c|c|c|c|}
\hline \multicolumn{12}{|c|}{ Flexible work schedules } \\
\hline AOS & 4 & 1106 & 0.25 & 0.25 & $* *$ & 0.17 & 0.15 & 0.09 & -0.42 & 24.48 & $* * *$ \\
\hline $\begin{array}{c}\text { Organizational } \\
\text { attractiveness }\end{array}$ & 11 & 2746 & 0.18 & 0.18 & $* * *$ & 0.11 & 0.41 & 0.11 & -0.25 & 25.05 & $* *$ \\
\hline \multicolumn{12}{|l|}{ Telecommuting } \\
\hline AOS & 3 & 846 & 0.21 & 0.22 & $* *$ & 0.14 & 0.24 & 0.06 & -0.37 & 12.09 & $* *$ \\
\hline $\begin{array}{c}\text { Organizational } \\
\text { attractiveness }\end{array}$ & 7 & 2171 & 0.14 & 0.14 & $* *$ & 0.12 & 0.28 & 0.05 & -0.23 & 21.23 & $* *$ \\
\hline \multicolumn{12}{|l|}{ Sabbaticals } \\
\hline AOS & 2 & 716 & - & - & & - & - & - & - & - & \\
\hline $\begin{array}{c}\text { Organizational } \\
\text { attractiveness }\end{array}$ & 4 & 987 & 0.29 & 0.30 & $* *$ & 0.19 & 1.00 & 0.11 & -0.49 & 2.87 & \\
\hline
\end{tabular}

$k$ The number of effect sizes, $N$ the total sample size, $r$ the sample-weighted mean correlation, $\rho$ the mean estimate of the corrected population correlation, $S D \rho$ the standard deviation of the mean estimate of the corrected population correlation, \% SE the percentage of variance attributable to sampling and measurement error, $95 \%$ CI the $95 \%$ confidence interval, $Q$ test for the total heterogeneity of true correlations across studies, AOS anticipated organizational support, - relationships were excluded from analysis if their frequency $k$ was less than 3

$* p<0.05, * * p<0.01, * * * p<0.001$

Supporting Hypotheses $2 \mathrm{a}, 2 \mathrm{~b}$, and 2c, flexible work schedules $(\rho=0.18,95 \%$ $\mathrm{CI}=0.11,0.25)$, telecommuting $(\rho=0.14,95 \% \mathrm{CI}=0.05,0.23)$ and sabbaticals $(\rho=0.30,95 \% \mathrm{CI}=0.11,0.49)$ are positively related to organizational attractiveness. The $Q$ tests for flexible work schedules $(p<0.001)$ and telecommuting $(p<0.05)$ are significant, while the one for sabbaticals is not. The non-significant $Q$ test indicates that the variance of the effect of sabbaticals is only due to sampling error.

Results for the direct effects of FWPs on internal outcomes are presented in Table 3. As predicted in Hypotheses $4 \mathrm{a}$ and $4 \mathrm{~b}$, the effects of flexible work schedules $(\rho=0.32,95 \% \mathrm{CI}=0.18,0.46)$ and telecommuting $(\rho=0.19,95 \%$ $\mathrm{CI}=0.06,0.32)$ on perceived autonomy are positive. The $Q$ tests are highly significant $(p<0.001)$. Hypothesis $4 c$, of a positive effect of sabbaticals on perceived autonomy, cannot be tested in this meta-analysis, because no primary study analyses this effect. Flexible work schedules $(\rho=0.19,95 \%$ CI $=0.12$, $0.26)$ and sabbaticals $(\rho=0.15,95 \% \mathrm{CI}=0.05,0.24)$ are positively related to organizational commitment, whereas the effect of telecommuting on organizational commitment is marginally non-significant $(\rho=0.08,95 \% \mathrm{CI}=-0.01,0.17)$. Moreover, flexible work schedules $(\rho=-0.05,95 \% \mathrm{CI}=-0.10,-0.01)$ and telecommuting ( $\rho=-0.10,95 \% \mathrm{CI}=-0.16,-0.04)$ are negatively related to turnover intention. Since only two primary studies test the effect of sabbaticals on turnover intention, this relationship cannot be investigated in a meta-analysis. All 


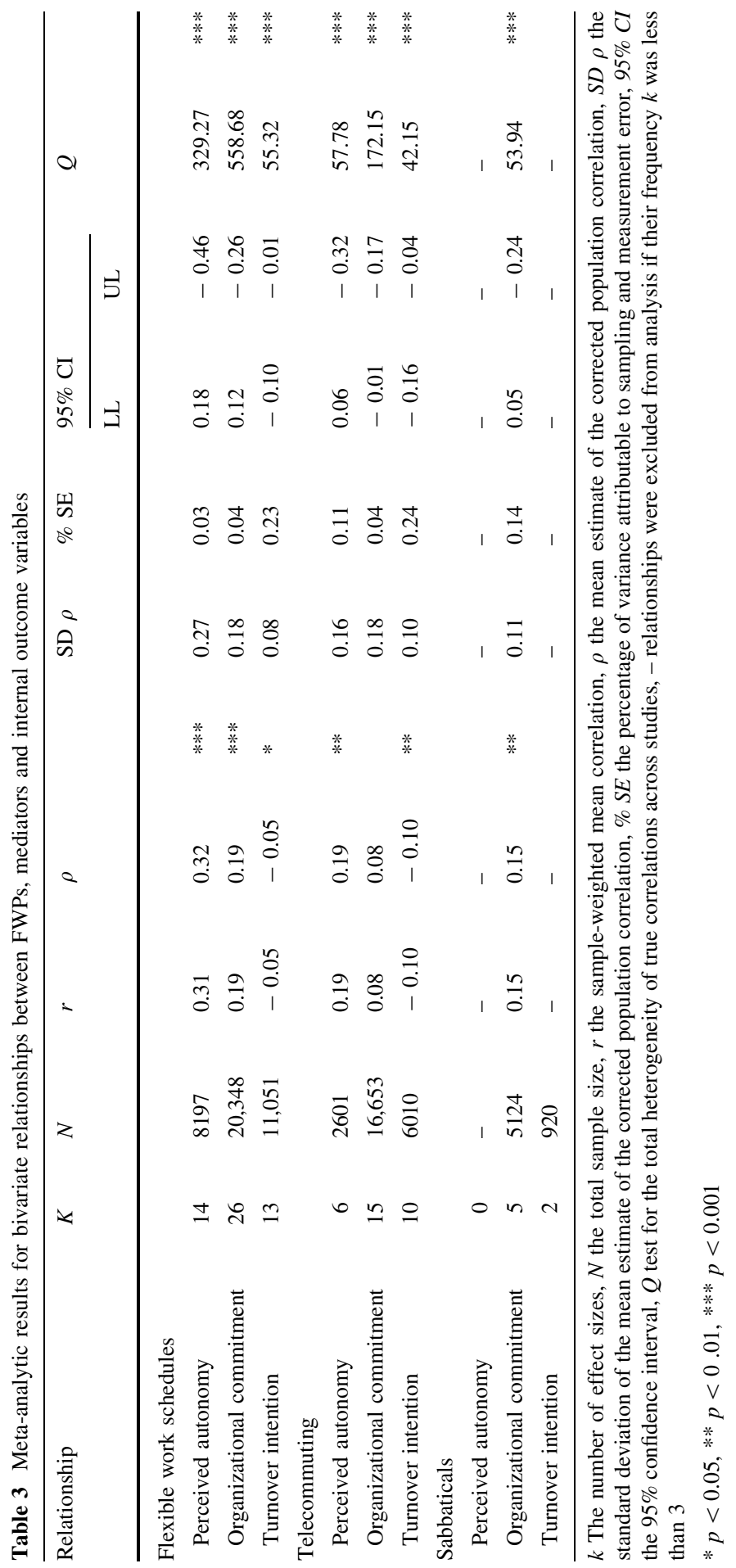


Table 4 Meta-analytic correlations between FWPs and external outcomes

\begin{tabular}{|c|c|c|c|c|c|}
\hline & & 1 & 2 & 3 & 4 \\
\hline 1. & Flexible work schedules & - & & & \\
\hline \multirow[t]{3}{*}{2.} & Telecommuting & $0.33^{\mathrm{b}}$ & - & & \\
\hline & $k$ & $21^{\mathrm{b}}$ & & & \\
\hline & $N$ & $52,111^{\mathrm{b}}$ & & & \\
\hline \multirow[t]{3}{*}{3.} & Sabbaticals & $0.22^{\mathrm{b}}$ & $0.19^{\mathrm{b}}$ & - & \\
\hline & $k$ & $2^{c}$ & $2^{\mathrm{j}}$ & & \\
\hline & $N$ & $839^{\mathrm{b}}$ & $839^{\mathrm{b}}$ & & - \\
\hline \multirow[t]{3}{*}{4.} & AOS & $0.25^{\mathrm{a}}$ & $0.22^{\mathrm{a}}$ & $0.37^{\mathrm{a}}$ & \\
\hline & $k$ & $4^{\mathrm{a}}$ & $3^{\mathrm{a}}$ & $2^{\mathrm{c}}$ & \\
\hline & $N$ & $1106^{\mathrm{a}}$ & $846^{\mathrm{a}}$ & $716^{\mathrm{a}}$ & \\
\hline \multirow[t]{3}{*}{5.} & $\begin{array}{l}\text { Organizational } \\
\text { attractiveness }\end{array}$ & $0.18^{\mathrm{a}}$ & $0.14^{\mathrm{a}}$ & $0.30^{\mathrm{a}}$ & $0.64^{\mathrm{b}}$ \\
\hline & $k$ & $11^{\mathrm{a}}$ & $7^{\mathrm{a}}$ & $4^{\mathrm{a}}$ & $4^{\mathrm{b}}$ \\
\hline & $N$ & $2746^{\mathrm{a}}$ & $2171^{\mathrm{a}}$ & $987^{\mathrm{a}}$ & $1106^{\mathrm{b}}$ \\
\hline
\end{tabular}

All correlations are corrected for unreliability and are derived from random effect meta-analytic techniques

$k$ The number of effect sizes, $N$ the total sample size, $A O S$ anticipated organizational support

${ }^{\text {a }}$ Original analysis in the current paper. Detailed information can be found in Table 2

${ }^{\mathrm{b}}$ Original analysis in the current paper; ${ }^{\mathrm{c}} k$ is actually too small for an investigation, but sufficient here

$Q$ tests concerning organizational attachment are highly significant $(p<0.001)$. Overall, our meta-analytic results support Hypothesis 5a that flexible work schedules increase organizational attachment and decrease turnover intention. Hypotheses $5 \mathrm{~b}$ and $5 \mathrm{c}$ are only partly supported because telecommuting does not significantly increase organizational commitment and because there were not sufficient primary studies to test the effect of sabbaticals on turnover intention.

\subsection{Model testing}

To test the mediation models, we use MASEM and the WLS estimation method and present the meta-analytic correlation matrices in Tables 4 and 5. At first, latent constructs were created, one to represent all three FWPs, flexible work schedules, telecommuting and sabbaticals, and a second to represent the two organizational attachment indicators, organizational commitment and turnover intention. Because no primary studies examine the effect of sabbaticals on perceived autonomy, we can only test the effects of flexible work schedules and telecommuting in the internal model. The proposed mediating variables and organizational attractiveness are manifest variables.

We use comparative fit index (CFI), Tucker-Lewis index (TLI), root-meansquare error of approximation (RMSEA), standardized root-mean-square residual (SRMR), and Akaike's information criteria (AIC) for evaluating model fits. CFI and 
Table 5 Meta-analytic correlations between FWPs and internal outcomes

\begin{tabular}{|c|c|c|c|c|c|}
\hline & & 1 & 2 & 3 & 4 \\
\hline 1. & Flexible work schedules & - & & & \\
\hline \multirow[t]{3}{*}{2.} & Telecommuting & $0.33^{\mathrm{b}}$ & - & & \\
\hline & $k$ & $21^{\mathrm{b}}$ & & & \\
\hline & $N$ & $52,111^{\mathrm{b}}$ & & & \\
\hline \multirow[t]{3}{*}{3.} & Perceived autonomy & $0.32^{\mathrm{a}}$ & $0.19^{\mathrm{a}}$ & - & \\
\hline & $k$ & $14^{\mathrm{a}}$ & $6^{\mathrm{a}}$ & & \\
\hline & $N$ & $8,197^{\mathrm{a}}$ & $2,601^{\mathrm{a}}$ & & \\
\hline \multirow[t]{3}{*}{4.} & $\begin{array}{r}\text { Organizational } \\
\text { commitment }\end{array}$ & $0.19^{\mathrm{a}}$ & $0.08^{\mathrm{a}}$ & $0.38^{\mathrm{c}}$ & - \\
\hline & $k$ & $26^{\mathrm{a}}$ & $15^{\mathrm{a}}$ & 6 & \\
\hline & $N$ & $20.348^{\mathrm{a}}$ & $16,653^{\mathrm{a}}$ & 702 & \\
\hline \multirow[t]{3}{*}{5.} & Turnover intention & $-0.05^{\mathrm{a}}$ & $-0.10^{\mathrm{a}}$ & $-0.15^{\mathrm{c}}$ & $-0.56^{\mathrm{d}}$ \\
\hline & $k$ & $13^{\mathrm{a}}$ & $10^{\mathrm{a}}$ & 11 & 51 \\
\hline & $N$ & $11,051^{\mathrm{a}}$ & $6.010^{\mathrm{a}}$ & 1667 & 1,7282 \\
\hline
\end{tabular}

$k$ The number of effect sizes, $N$ the total sample size; All correlations are corrected for unreliability and are derived from random effect meta-analytic techniques

${ }^{a}$ Original analysis in the current paper. Detailed information can be found in Table 2

${ }^{\mathrm{b}}$ Original analyses in the current paper

c Spector (1986)

${ }^{\mathrm{d}}$ Meyer et al. (2002)

Table 6 Fit statistics for hypothesized and alternative model comparisons

\begin{tabular}{|c|c|c|c|c|c|c|c|c|c|c|}
\hline Model & $\chi^{2}$ & & $d f$ & CFI & TLI & RMSEA & SRMR & AIC & $\Delta \chi^{2}$ & \\
\hline \multicolumn{11}{|c|}{ Organizational attractiveness (external) } \\
\hline Model A: full mediation & 82.66 & $* * *$ & 9 & 0.95 & 0.95 & 0.08 & 0.08 & 64.66 & & \\
\hline $\begin{array}{l}\text { Model B: partial } \\
\text { mediation }\end{array}$ & 43.98 & $* * *$ & 8 & 0.97 & 0.98 & 0.06 & 0.06 & 27.98 & 38.67 & $* * *$ \\
\hline \multicolumn{11}{|l|}{$\begin{array}{l}\text { Organizational attachment } \\
\text { (internal) }\end{array}$} \\
\hline Model C: full mediation & 74.50 & $* * *$ & 8 & 0.98 & 0.98 & 0.05 & 0.04 & 58.50 & & \\
\hline $\begin{array}{l}\text { Model D: partial } \\
\text { mediation }\end{array}$ & 42.00 & $* * *$ & 7 & 0.99 & 0.99 & 0.04 & 0.02 & 28.00 & 32.50 & $* * *$ \\
\hline
\end{tabular}

$d f$ Degrees of freedom, CFI comparative fit index, TLI Tucker-Lewis index, RMSEA root-mean-square error of approximation, SRMR standardized root-mean-square residual, AIC Akaike's information criteria, $A O S$ anticipated organizational support

$* p<0.05$, ** $p<0.01$, *** $p<0.001$

TLI greater than 0.90, SRMR less than 0.08 and RMSEA less than 0.10 indicate an acceptable fit (Browne and Cudeck 1993; MacCallum et al. 1996). In Table 6, we compare the fit statistics of the full mediation models with alternative partial mediation models, which also entail direct effects of FWPs on organizational 


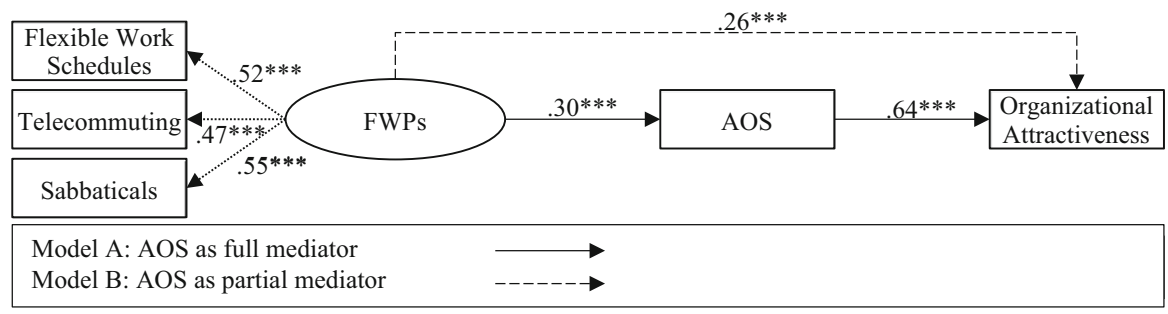

Fig. 3 Model linking FWPs to external outcomes. FWPs flexible work practices, AOS anticipated organizational support; values represent standardized coefficients for model $\mathrm{B}$; *** $p<0.001$

attractiveness and organizational attachment. The models are compared by testing whether significant differences in Chi-squared occurred (Hu and Bentler 1999) that have to be supported by the AIC measures, because they are less sensitive in large samples (Bearden et al. 1982; Butts et al. 2013).

The model fit statistics of the external model A, which considers anticipated organizational support as a full mediator, are acceptable $\left(\chi_{(9)}^{2}=82.66\right.$, CFI $=0.95$, $\mathrm{TLI}=0.95, \mathrm{RMSEA}=0.08, \mathrm{SRMR}=0.08, \mathrm{AIC}=64.66)$. However, the external model B, which considers anticipated organizational support as a partial mediator and also allows for a direct effect of FWPs on organizational attractiveness, has significantly better model fit measures $\left(\Delta \chi^{2}=38.67\right.$, $p<0.001 ; \Delta \mathrm{AIC}=36.68)$, supporting Hypothesis 3 . The direct effect of FWPs on organizational attractiveness is significantly positive $(\beta=0.26, p<0.001)$. All path coefficients in model B are highly significant $(p<0.001)$ and are presented in Fig. 3. The indirect effect of FWPs on organizational attractiveness is 0.19 $(p<0.05)$.

The model fit statistics of the internal model $\mathrm{C}$, which considers perceived autonomy as full mediator, are $\operatorname{good}\left(\chi_{(8)}^{2}=74.50, \mathrm{CFI}=0.98\right.$, TLI $=0.98$, $\mathrm{RMSEA}=0.05, \mathrm{SRMR}=0.04$, AIC $=58.50$ ). However, the internal model $\mathrm{D}$, which considers perceived autonomy as a partial mediator and also allows for a direct effect of FWPs on organizational attachment, has significantly better model fit measures $\left(\Delta \chi^{2}=32.50, p<0.001 ; \Delta \mathrm{AIC}=30.50\right)$, supporting Hypothesis 6 . The direct effect of FWPs on organizational attachment is significantly positive $(\beta=0.17, \quad p<0.001)$. All coefficients of model $\mathrm{D}$ are highly significant $(p<0.001)$ and are presented in Fig. 4. The indirect effect of FWPs on organizational attachment is $0.14(p<0.05)$.

\subsection{Comparison of effects}

The positive effect of an FWP on organizational attractiveness is larger for sabbaticals $(\rho=0.30)$ than for flexible work schedules $(\rho=0.18)$ or telecommuting $(\rho=0.14)$. To test for the significance of the differences, we conducted $z$ tests of mean comparison. Both the differences in effect sizes between sabbaticals and flexible work schedules $(z=3.52, p<001)$ and between sabbaticals and 


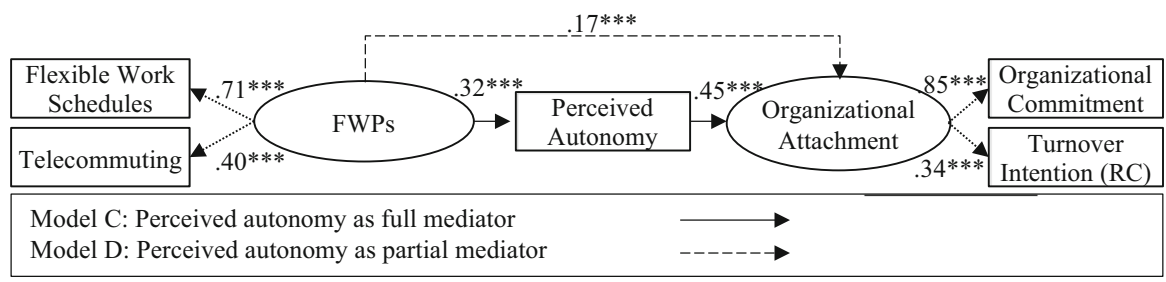

Fig. 4 Model linking FWPs to internal outcomes. FWPs flexible work practices; sabbaticals missed as FWP indicator due to a lack of studies, $R C$ reversely coded; values represent standardized coefficients for model D; $* * * p<0.001$

telecommuting $(z=4.41, p<0.001)$ are statistically significant, which confirms Hypothesis 7a.

The positive effect of an FWP on organizational attachment was larger for sabbaticals $(\rho=0.14)$ than for telecommuting $(\rho=0.09)$ but smaller than for flexible work schedules $(\rho=0.15)$. The $z$ tests show that sabbaticals have significantly stronger positive effects on organizational attachment than telecommuting $(z=4.21, p<0.001)$, whereas the differences in effect sizes between sabbaticals and flexible work schedules are not significant $(z=0.65, n s$. $)$. Hence, Hypothesis $7 \mathrm{~b}$ is only partially supported.

\subsection{Moderator analyses}

The mostly significant $Q$ values indicate substantial heterogeneity and the potential influence of moderators. As moderator analyses with small sample sizes and a low number of primary studies are very sensitive (Shadish and Sweeney 1991), we aggregate FWPs to one construct to increase the sample size. While we test the moderator quality of primary study on both external and internal outcomes, we examine the moderation effect of availability versus use of FWPs only on internal outcomes, because job seekers have not yet had the opportunity to use FWPs.

Table 7 shows that availability versus use of FWPs acts as moderator, because the availability of FWPs has significant larger effects than the use of FWPs on perceived autonomy $\left(Q_{\mathrm{M}}=25.69, p<0.001\right)$ and on organizational attachment $\left(Q_{\mathrm{M}}=45.93, p<0.001\right)$, confirming Hypothesis 8c and 8d. Hypotheses 8a and 8b, predicting stronger effects in case of mere availability of FWPs compared to use of FWPs on anticipated organizational support and perceived autonomy, are not supported.

Table 8 shows that when using the Study DIAD approach, the quality of the primary studies significantly decreases the relationship between FWPs and organizational attractiveness $\left(Q_{\mathrm{M}}=7.64, p<0.01\right)$. The moderating influences of study quality on anticipated organizational support, perceived autonomy and organizational attachment are not statistically significant.

Table 9 shows the results when measuring the quality of the primary studies with the Journal Impact Factor. Because the Journal Impact Factor is only available for published studies, this analysis has a smaller sample size, lower statistical power 


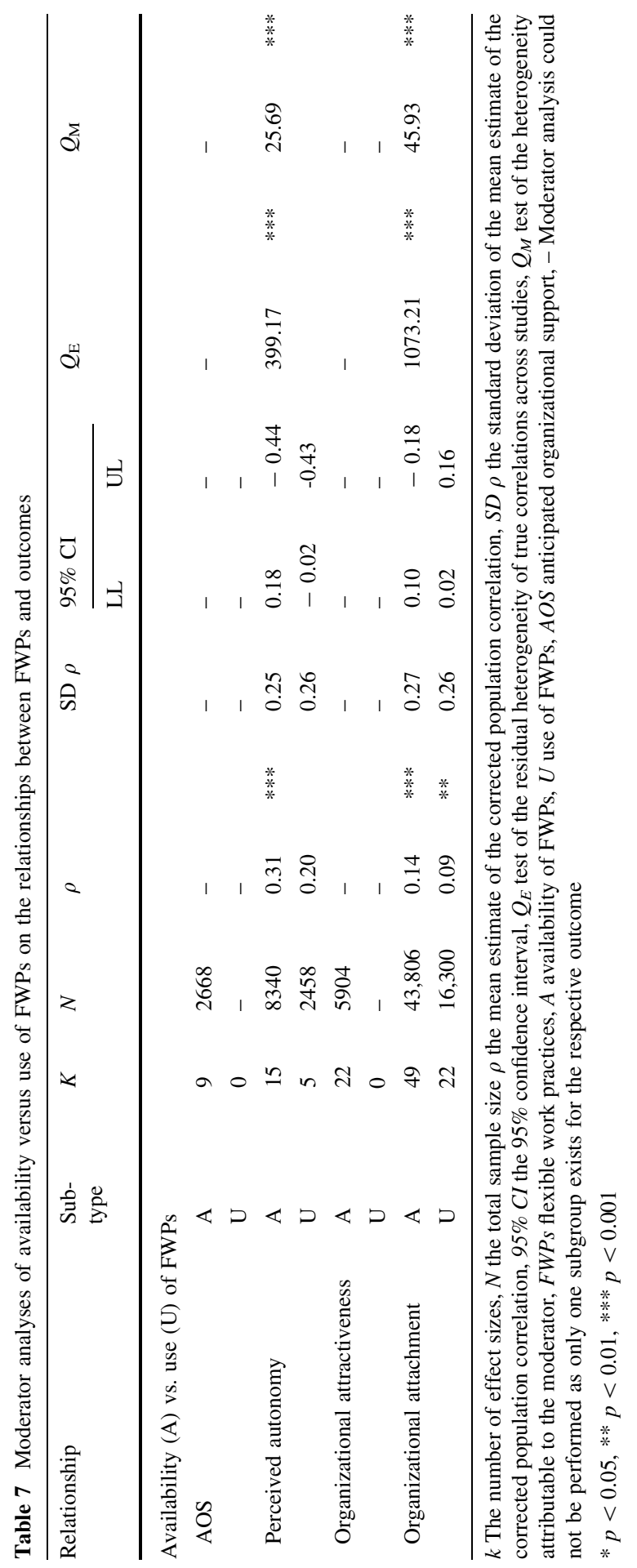




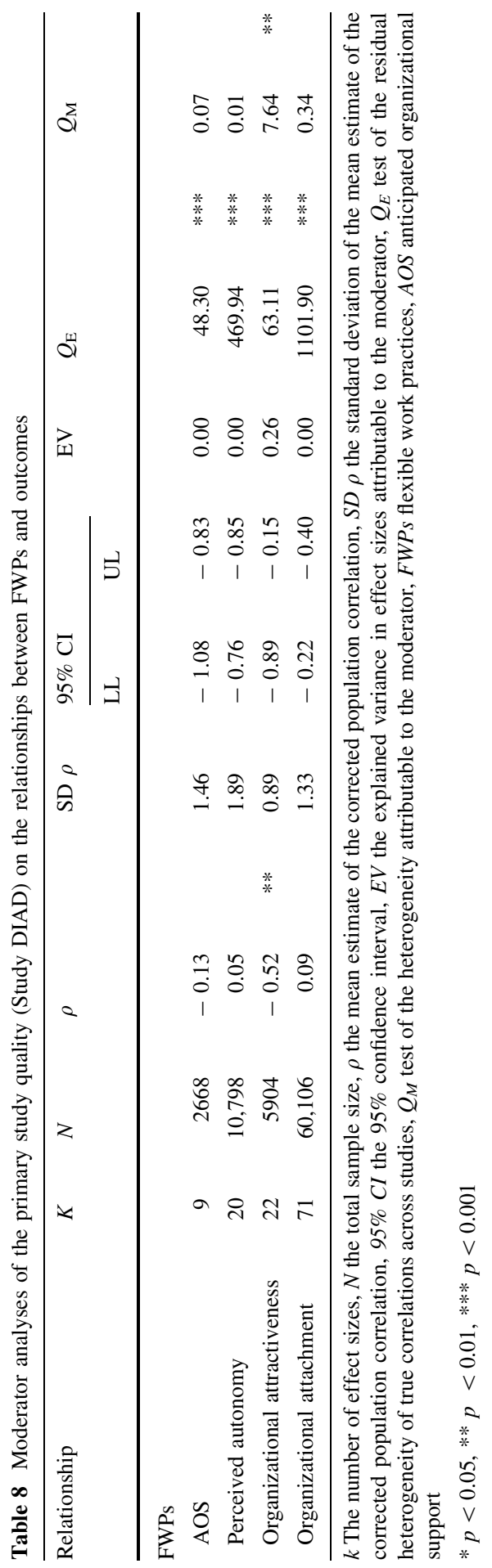


Table 9 Moderator analyses of the primary study quality (journal impact factor) on the relationships between FWPs and outcomes

\begin{tabular}{|c|c|c|c|c|c|c|c|c|c|}
\hline \multirow[t]{2}{*}{ Relationship } & \multirow[t]{2}{*}{$K$} & \multirow[t]{2}{*}{$N$} & \multirow[t]{2}{*}{$\rho$} & \multirow{2}{*}{$\begin{array}{l}\text { SD } \\
\rho\end{array}$} & $95 \%$ & & \multirow[t]{2}{*}{ EV } & $Q_{\mathrm{E}}$ & \multirow[t]{2}{*}{$Q_{\mathrm{M}}$} \\
\hline & & & & & LL & UL & & & \\
\hline
\end{tabular}

\begin{tabular}{|c|c|c|c|c|c|c|c|c|c|c|}
\hline \multicolumn{11}{|l|}{ FWPs } \\
\hline AOS & 3 & 520 & -0.12 & 0.29 & -0.32 & -0.95 & 0.00 & 48.30 & $* * *$ & 0.49 \\
\hline Perceived Autonomy & 15 & 9358 & 0.03 & 0.22 & -0.09 & -0.14 & 0.00 & 469.94 & $* * *$ & 0.23 \\
\hline $\begin{array}{c}\text { Organizational } \\
\text { attractiveness }\end{array}$ & 10 & 1403 & -0.02 & 0.08 & -0.07 & -0.03 & 0.00 & 17.43 & $*$ & 0.78 \\
\hline $\begin{array}{l}\text { Organizational } \\
\text { attachment }\end{array}$ & 51 & 47,365 & -0.03 & 0.14 & -0.07 & -0.01 & 0.01 & 937.88 & $* * *$ & 2.15 \\
\hline
\end{tabular}

$k$ The number of effect sizes, $N$ the total sample size, $\rho$ the mean estimate of the corrected population correlation, $S D \rho$ the standard deviation of the mean estimate of the corrected population correlation, $95 \%$ $C I$ the $95 \%$ confidence interval, $E V$ the explained variance in effect sizes attributable to the moderator, $Q_{E}$ test of the residual heterogeneity of true correlations across studies, $Q_{M}$ test of the heterogeneity attributable to the moderator, FWPs flexible work practices, AOS anticipated organizational support

$* p<0.05, * * p<0.01, * * * p<0.001$

and excludes unpublished work. All moderating effects are found to be statistically insignificant. Hypotheses 9a, 9b, 9c, and 9d are therefore not confirmed.

\subsection{Sensitivity analyses}

To check the robustness of the meta-analysis results, we conducted two types of sensitivity analyses (Borenstein et al. 2009). Because significant findings are more likely to be published than non-significant results, leading to an overestimation of the effects (Rosenthal 1979), we first control for a publication bias. For each of our outcomes, we conducted the Egger test, which examines whether the respective funnel plot of a relationship shows a significant asymmetry (Egger et al. 1997). The Egger tests are not statistically significant, which indicates the absence of a publication bias in our study. Ferguson and Brannick (2012) recommend to conduct two different publication bias tests to underline the robustness of findings. Therefore, we also conducted the Trim-and-Fill method, which trims unmatched values around the initial estimate and fills the funnel plot with imputed missing studies in an iterative process to achieve symmetric funnel plots (Duval and Tweedie 2000). We compared the initial and new estimators to identify remarkable changes. In two cases, trim-and-fill adjustments were made, whereby the effect sizes changed only marginally and the significance levels remained constant.

Second, we checked whether the results change when eliminating outliers using the procedures of Viechtbauer and Cheung (2010). In two cases the significance levels of the relationships, of telecommuting with organizational attractiveness and with turnover intention, increased from $p<0.01$ to $p<0.001$. The other results show no notable changes, although the $\mathrm{Q}$ value that tests for heterogeneity decreases considerably in all cases. 


\section{Discussion}

The overall aim of this study was to investigate the question of whether and how FWPs are related to organizational attractiveness and organizational attachment. For these purposes, two kinds of examinations were conducted. Firstly, we explored bivariate relationships between FWPs and external and internal outcomes by performing a quantitative review. Secondly, we developed and tested two mediation models that linked FWPs to organizational attractiveness through anticipated organizational support and FWPs to organizational attachment through perceived autonomy, respectively.

\subsection{Key findings}

Concerning the external outcomes and hence focusing on anticipated organizational support and organizational attractiveness, our meta-analytic results indicate that flexible work schedules, telecommuting and sabbaticals are related to increased anticipated organizational support and organizational attractiveness. Following Cohen's benchmarks, the effect sizes of all three FWPs are small to moderate (e.g. Cohen 1988). However, when comparing effect sizes, sabbaticals increase organizational attractiveness more strongly than flexible work schedules and telecommuting. Because sabbaticals are (still) less common than flexible work schedules and telecommuting (Society for Human Resource Management 2015), job seekers may feel a special privilege when they enter an organization that offers sabbaticals. Moreover, the opportunity for a longer paid leave from work sounds very desirable (Carr and Tang 2005).

Our meta-analysis also attempted to clarify how FWPs are linked to organizational attractiveness. Applying organizational support theory and signalling theory, we find evidence that anticipated organizational support partially mediates the relationship between FWPs and organizational attractiveness, which is in line with the recent study by Thompson et al. (2015). By offering FWPs, organizations signal that they care for their employees. The fact that anticipated organizational support only partially mediates the relationship indicates that there may be additional channels how FWPs affect organizational attractiveness beyond anticipated organizational support. Butts et al. (2013), for example, suggested legitimacy as a channel. They find that FWPs are desired by individuals regardless of whether FWPs are anticipated as supportive.

The internal outcomes perceived autonomy and organizational commitment are also positively affected by FWPs whereby FWPs have a negative relationship with turnover intention. FWPs improve the perceived autonomy of existing employees and their attachment to their organizations, both when measuring organizational attachment as organizational commitment and as (an absence of) turnover intention. All effects are statistically significant except for the marginally insignificant effect of telecommuting on organizational commitment. The latter effect can be explained by the positive and negative aspects of telecommuting that may neutralize each other. On the one hand, telecommuting blurs the boundary between work and 
private life (Hill et al. 2003; Igbaria and Guimaraes 1999) and, thus, leads to a greater integration of work and non-work roles (Rau and Hyland 2002). As a consequence, telecommuting may lead to prolonged workdays and increased demand of extensive availability (Heijstra and Rafnsdottir 2010). Moreover, employees often fear to be isolated when using telecommuting (Kurland and Cooper 2002; Golden and Veiga 2008). On the other hand, telecommuting increases the perceived autonomy of employees (Gajendran and Harrison 2007), helps in coordinating work and private obligations (Duxbury et al. 1998; Harpaz 2002) and reduces commuting time (Raghuram and Wiesenfeld 2004).

A comparison of the effect sizes shows that the effect sizes of sabbaticals and flexible work schedules on organizational attachment are similar. However, the fact that sabbaticals have a significantly stronger effect on organizational attachment than telecommuting indicates that employees consider telecommuting to be less beneficial than sabbaticals and flexible work schedules. As mentioned above, and in contrast to flexible work schedules, telecommuting presents various disadvantages for employees, such as social and professional isolation. Hence, although both practices offer regular flexibility, employees prefer flexible work schedules to telecommuting, because flexible work schedules provide daily working time flexibility without the significant drawbacks of telecommuting. Employees may also value sabbaticals more than telecommuting because they allow employees to fulfil personal dreams, like a trip around the world, while still having job security as they do not lose their legal rights as employees.

We find evidence that the effect of FWPs on organizational attachment is partially mediated by perceived autonomy. It is, therefore, crucial to not only implement FWPs but to ensure that employees perceive autonomy regarding when, where and how long they work (e.g. Gajendran and Harrison 2007). For example, organizations should ensure that flexible work agreements do not dictate activities and performance levels with high intensity, because this would diminish employees * perception of autonomy (Gurstein 2001).

Because perceived autonomy only partially mediates the relationship between FWPs and organizational attachment, there might be other mediators. Gajendran and Harrison (2007), for example, found work-family conflict and relationship quality with supervisor as mediators of the effects of telecommuting on work attitudes.

A further finding is that it matters whether the primary studies measured the effects of the availability of FWPs or of the use of FWPs. More precisely, the availability of FWPs is more strongly related to perceived autonomy and organizational attachment than the use of FWPs, which corroborates the findings of prior studies (e.g. Butts et al. 2013; Allen et al. 2013). This finding indicates that the availability of FWPs already suffices to signal perceived autonomy besides other positive attitudes and values (Batt and Valcour 2003; Grover and Crooker 1995) and to increase organizational attachment as individuals are more attached when they feel valued and trusted through the mere offer of FWPs. When using FWPs employees may also experience potential drawbacks of FWPs such as social isolation, which tends to weaken the positive effects of FWPs. 
When the quality of the primary studies was included as a moderator in the models, the relationships were not statistically significant, indicating that the quality of the primary studies does not influence the effect sizes, in all but one case. The exception was that study quality decreased the effect size of FWPs on organizational attractiveness when we measured study quality by the Study DIAD. However, this moderating influence also becomes statistically insignificant when we measure the study quality of published work by the Journal Impact Factor, which is a more objective proxy than the somewhat subjective Study DIAD proxy.

\subsection{Limitations and directions for future research}

Despite the significant contributions of this study, it is not without limitations. One restriction is the fact that this meta-analysis displays correlations and not necessarily causal effects. To identify causal effects, field experiments with treatment and control groups and random allocations of employees to one of these groups would be helpful. Performing quasi-experiments that include design features like removed treatment may enhance the internal validity (Shadish et al. 2002), because randomized experiments are often impractical or unethical in our context. Statistical techniques like propensity score matching may also facilitate the identification of causal effects (e.g. Guo and Fraser 2014).

Another problem is the low frequency of primary studies that analyse the effects of FWPs, especially of sabbaticals, on anticipated organizational support, perceived autonomy, and turnover intention. While several primary studies analysed the effects of flexible work schedules, few primary studies analysed the effects of telecommuting and hardly any primary study analysed the effects of sabbaticals. Hence, additional studies are needed to address these under-researched areas.

The fact that anticipated organizational support and perceived autonomy only partially mediate the relationships between organizational attractiveness and organizational attachment, respectively, indicates that there might be other mediators. We encourage future studies to test for different mediators, such as a perceived value fit (e.g. Chapman et al. 2005) in addition to anticipated organizational support when analysing the effects of FWPs on organizational attractiveness, and a perceived work-life conflict (e.g. Butts et al. 2013) in addition to perceived autonomy when analysing the effects of FWPs on organizational attachment.

The highly significant residual heterogeneity statistic $Q$ indicates that further factors may moderate the relationships between FWPs and organizational attractiveness and organizational attachment, like gender (e.g. Scandura and Lankau 1997), age (e.g. Ng and Feldman 2009), or the work/non-work interface (Grawitch et al. 2011). Thereby, the work/non-work interface should not only concentrate on family related issues like previous papers (e.g. Allen 2001; Butts et al. 2013), but should also integrate volunteerism, hobbies and other roles (Grawitch et al. 2011). In addition, the origin of the study might act as a moderator due to different employee protection rights in different countries.

Another limitation is that the usage of FWPs is measured as a dichotomous variable. We encourage future research to measure the intensity of the use of FWPs 
on a continuous scale, which could also be included in the existing model as a moderating variable (e.g. Golden and Veiga 2008). For example, if the number of days working from home is restricted, the negative consequences of telecommuting (e.g. isolation, blurring boundaries) are less intense (Golden and Veiga 2008; Rau and Hyland 2002).

We also encourage longitudinal research that observes the same individuals before and after entering an organization with or without FWPs. Such longitudinal research could not only control for time-constant individual heterogeneity, but could also test the influence of expectations. This is important, because discrepancies between the promises made in the recruiting process and internal reality are problematic (Haar 2008). When a job seeker decides to work for a specific company partly on the basis of the offer of FWPs, realizing the downsides of FWPs or facing co-workers or supervisors criticizing the use of FWPs could lead to disappointments. Such negative emotions could be counterproductive to the aim of introducing FWPs. Employers do well to ensure consistency between the promises made in the recruiting process and the internal reality. This implies that introducing FWPs has to be accompanied by supervisor training and an organizational culture that welcomes making use of FWPs (Mulvaney 2011).

A further avenue for future research is to specifically address the interdependencies between the evaluations of job seekers and employees. The studies of Dutton and Dukerich (1991) and Knox and Freeman (2006) suggest that existing employees pay high attention to external evaluations of the employer attractiveness, while job seekers are also influenced by testimonials of employees on online platforms or given by personal contacts (Gotsi and Wilson 2001).

\subsection{Practical implications}

Our results indicate that organizations should implement flexible work schedules, telecommuting and sabbaticals to attract job seekers. Offering FWPs serves as a signal to job seekers that the organization will care about the employees "wellbeing and thus increases organizational attractiveness. As a consequence, individuals are more likely to apply to such organizations, which enlarge the talent pool from which these organizations can select the best talents. Moreover, the more highly an applicant evaluates the organizational attractiveness, the more likely the applicant is to accept a job offer (Chapman et al. 2005). The fact that sabbaticals have the strongest positive relationship with organizational attractiveness indicates that offering sabbaticals may create a unique selling proposition in the job market and may thus be particularly helpful in acquiring the best talents.

Offering FWPs is not only related to the job seeker's perception of organizational attractiveness, but also increases the organizational attachment and retention rate of the existing employees. Because turnover intention is closely linked to the actual employee turnover (Steel et al. 1990), we can conclude that FWPs reduce the turnover rate. This not only saves money on hiring and training new employees (Halpern 2005), but also helps the organization to keep employees with specific human capital (Campbell et al. 2012). As the effect of FWPs on organizational attachment is partially mediated by perceived autonomy, organizations should make 
sure that everyday work is organized in such a way that employees experience autonomy. The intensity of work assignments and performance expectations should be independent of whether someone uses FWPs or not (e.g. Gurstein 2001; Harrison et al. 2000). Our findings further indicate that the availability of FWPs already increases organizational attachment regardless of whether employees personally use FWPs. The opportunity to make use of FWPs when needed suffices to increase the perceived autonomy.

\section{Conclusion}

Offering flexible work practices (FWPs) is an effective strategy to attract job seekers and retain employees. This meta-analysis shows that flexible work schedules, telecommuting and sabbaticals have positive relationships with organizational attractiveness that are mediated through anticipated organizational support. Furthermore, FWPs are positively related to organizational attachment because of increased perceived autonomy. We hope that this meta-analysis will stimulate future analyses of the underlying processes by which FWPs can help organizations in attracting and retaining talented employees.

Open Access This article is distributed under the terms of the Creative Commons Attribution 4.0 International License (http://creativecommons.org/licenses/by/4.0/), which permits unrestricted use, distribution, and reproduction in any medium, provided you give appropriate credit to the original author(s) and the source, provide a link to the Creative Commons license, and indicate if changes were made.

\section{References}

References marked with an asterisk indicate studies included in the current meta-analysis.

Allen, T.D. 2001. Family-supportive work environments: the role of organizational perceptions. Journal of Vocational Behavior 58: 414-435. https://doi.org/10.1006/jvbe.2000.1774.

Allen, T.D., R.C. Johnson, K.M. Kiburz, and K.M. Shockley. 2013. Work-family conflict and flexible work arrangements: deconstructing flexibility. Personnel Psychology 66: 345-376. https://doi.org/ 10.1111/peps.12012.

*Altmann, S., and S. Süß. 2015. The influence of temporary time offs from work on employer attractiveness-an experimental study. Management Revue 26: 282-305. https://doi.org/10.1688/ mrev-2015-04-Altmann.

*Amirbakhtiyarvand, F., Niya, S. J., Kheirandish, M. 2014. The studding of the teleworking relationship with organizational commitment (Allen and Meyer's model), Kuwait Chapter of the Arabian Journal of Business and Management Review, 3, 287-295. http://www.arabianjbmr.com/pdfs/KD_ VOL_3_9/28.pdf. Accessed 5 Dec 2017.

*Anderson, S.E., B.S. Coffey, and R.T. Byerly. 2002. Formal organizational initiatives and informal workplace practices: links to work-life conflict and job-related outcomes. Journal of Management 28: 787-810. https://doi.org/10.1177/014920630202800605.

*Aryee, S. 1992. Antecedents and outcomes of work-family conflict among married professional women: evidence from Singapore. Human Relations 45: 813-837. https://doi.org/10.1177/ 001872679204500804.

Bal, P.M., and A.H. de Lange. 2015. From flexibility human resource management to employee engagement and perceived job performance across the lifespan: a multisample study. Journal of Occupational and Organizational Psychology 88: 126-154. https://doi.org/10.1111/joop.12082. 
Bailey, D.E., and N.B. Kurland. 2002. A review of telework research: findings, new directions, and lessons for the study of modern work. Journal of Organizational Behavior 23: 383-400. https://doi. org/10.1002/job.144.

Baltes, B.B., T.E. Briggs, J.W. Huff, J.A. Wright, and G.A. Neuman. 1999. Flexible and compressed workweek schedules: a meta-analysis of their effects on work-related criteria. Journal of Applied Psychology 84: 496-513. https://doi.org/10.1037/0021-9010.84.4.496.

Batt, R., and P.M. Valcour. 2003. Human resources practices as predictors of work-family outcomes and employee turnover. Industrial Relations: A Journal of Economy and Society 42: 189-220. https:// doi.org/10.1111/1468-232X.00287.

Bearden, W.O., S. Sharma, and J.E. Teel. 1982. Sample size effects on Chi-square and other statistics used in evaluating causal models. Journal of Marketing Research 19: 425-430. https://doi.org/10. $2307 / 3151716$.

*Behson, S.J. 2002. Coping with family-to-work conflict: the role of informal work accommodations to family. Journal of Occupational Health Psychology 7: 324-341. https://doi.org/10.1037/1076-8998. 7.4.324.

*Behson, S.J. 2005. The relative contribution of formal and informal organizational. Journal of Vocational Behavior 66: 487-500. https://doi.org/10.1016/j.jvb.2004.02.004.

Bentler, P.M., and C-Ph Chou. 1987. Practical issues in structural modeling. Sociological Methods and Research 16: 87-117. https://doi.org/10.1177/0049124187016001004.

Borenstein, M., L.V. Hedges, J.P.T. Higgins, and H.R. Rothstein. 2009. Introduction to meta-analysis. Weinheim: Wiley.

Bothma, C.F.C., and G. Roodt. 2013. The validation of the turnover intention scale. SA Journal of Human Resource Management 11: 1-12. https://doi.org/10.4102/sajhrm.v11i1.507.

*Bourhis, A., and R. Mekkaoui. 2010. Beyond work-family balance: are family-friendly organizations more attractive? Industrial Relations 65: 98-117. https://doi.org/10.7202/039529ar.

Browne, M.W., and R. Cudeck. 1993. Alternative ways of assessing model fit. In Testing structural equation models, ed. K.A. Bollen, and J.S. Long, 136-162. Beverly Hills: Sage.

*Brummelhuis, L.L.T., and T. van der Lippe. 2010. Effective work-life balance support for various household structures. Human Resource Management 49: 173-193. https://doi.org/10.1002/hrm. 20340.

Butts, M.M., W.J. Casper, and T.S. Yang. 2013. How important are work-family support policies? A Meta-analytic investigation of their effects on employee outcomes. Journal of Applied Psychology 98: 1-25. https://doi.org/10.1037/a0030389.

Cable, D.M., L. Aiman-Smith, P.W. Mulvey, and J.R. Edwards. 2000. The sources and accuracy of job applicants' beliefs about organizational culture. Academy of Management Journal 43: 1076-1085. https://doi.org/10.2307/1556336.

Campbell, B.A., R. Coff, and D. Kryscynski. 2012. Rethinking sustained competitive advantage from human capital. Academy of Management Review 37: 376-395. https://doi.org/10.5465/amr.2010. 0276.

CareerArc. 2015. The 2015 Employer Branding Study. http://web.careerarc.com/2015-employerbranding-study.html. Accessed 5 Dec 2017.

Carr, A.E., and L.-P. Tang. 2005. Sabbaticals and employee motivation: benefits, concerns and implications. Journal of Education for Business 80: 160-164. https://doi.org/10.3200/JOEB.80.3. 160-164.

Casper, W.J., and L.C. Buffardi. 2004. Work-life benefits and job pursuit intention: the role of anticipated organizational support. Journal of Vocational Behavior 65: 391-410. https://doi.org/10.1016/j.jvb. 2003.09.003.

Casper, W.J., and C. Harris. 2008. Work-life benefits and organizational attachment: self-interest utility and signaling theory models. Journal of Vocational Behavior 72: 95-109. https://doi.org/10.1016/j. jvb.2007.10.015.

Chang, C.-H., C.C. Rosen, and P.E. Levy. 2009. The relationship between perceptions of organizational politics and employee attitudes, strain, and behavior: a meta-analytic examination. Academy of Management Journal 52: 779-801. https://doi.org/10.5465/AMJ.2009.43670894.

Chapman, D.S., K.L. Uggerslev, S.A. Carroll, K.A. Piasentin, and D.A. Jones. 2005. Applicant attraction to organizations and job choice: a meta-analytic review of the correlates of recruiting outcomes. Journal of Applied Psychology 90: 928-944. https://doi.org/10.1037/0021-9010.90.5.928.

Cheung, M.W.-L. 2015. metaSEM: an R package for meta-analysis using structural equation modeling. Frontiers in Psychology 5: 1521. https://doi.org/10.3389/fpsyg.2014.01521. 
Cheung, M.W.-L., and W. Chan. 2005. Meta-analytic structural equation modeling: a two-stage approach. Psychological Methods 10: 40-64. https://doi.org/10.1037/1082-989X.10.1.40.

*Chow, I. H.-S., and Keng-Howe, I. C. 2006. The effect of alternative work schedules on employee performance, International Journal of Employment Studies, 14, 105-130. http://web.b.ebscohost. com/ehost/pdfviewer/pdfviewer?sid=ff39721b-9598-4cb8-9907-8aadd0d2a3a3\%40sessionmgr105 andvid=0andhid=105. Accessed 5 Dec 2017.

*Clark, M.A., C.W. Rudolph, L. Zhdanova, J.S. Michel, and B.B. Baltes. 2015. Organizational support factors and work-family outcomes: exploring gender differences. Journal of Family Issues. https:// doi.org/10.1177/0192513X15585809.

Cohen, J. 1988. Statistical power analysis for the behavioral sciences, 2nd ed. Hillside: Erlbaum.

Davidson, O.B., D. Eden, M. Westman, Y. Cohen-Carash, L.B. Hammer, A.N. Kluger, M. Krausz, C. Maslach, M. O’Driscoll, P.L. Perrewé, J.C. Quick, Z. Rosenblatt, and P. Spector. 2010. Sabbatical leave: who gains and how much? Journal of Applied Psychology 95: 953-964. https://doi.org/10. $1037 / \mathrm{a} 0020068$.

Dineen, B.R., and D.G. Allen. 2016. Third party employment branding: human capital inflows and outflows following 'best places to work' certifications. Academy of Management Journal 59: 1-13. https://doi.org/10.5465/amj.2013.1091.

*Dubose, S. 2011. What attracts older nurses to organizations? Psychological moderators of the impact of flexible scheduling and mentoring opportunities, All Theses, Paper 1090. http://tigerprints.clemson. edu/all_theses/1090. Accessed 5 Dec 2017.

Dutton, J.E., and J.M. Dukerich. 1991. Keeping an eye on the mirror-image and identity in organizational adaptation. The Academy of Management Journal 34: 517-554. https://doi.org/10.2307/256405.

Duval, S., and R. Tweedie. 2000. Trim and Fill: a simple funnel-plot-based method of testing and adjusting for publication bias in meta-analysis. Biometrics 56: 455-563. https://doi.org/10.1111/j. 0006-341X.2000.00455.x.

Duxbury, L., C. Higgins, and D. Neufeld. 1998. Telework and the balance between work and family: Is telework part of the problem or part of the solution? In The Virtual Workplace, ed. M. Igbaria, and M. Tan, 218-255. Hershey: Idea Group.

Egger, M., G.D. Smith, M. Schneider, and C. Minder. 1997. Bias in meta-analysis detected by a simple, graphical test. British Medical Journal 315: 629-634. https://doi.org/10.1136/bmj.315.7109.629.

Eisenberger, R., R. Huntington, S. Hutchison, and D. Sowa. 1986. Perceived organizational support. Journal of Applied Psychology 71: 500-507. https://doi.org/10.1037/0021-9010.71.3.500.

*Farmer, L. 2015. When being more different and less visible leads to commitment and justice for all, Doctor of Business Administration Dissertations, Paper 8. http://digitalcommons.kennesaw.edu/ dba_etd/8. Accessed 5 Dec 2017.

Ferguson, C.J., and M.T. Brannick. 2012. Publication bias in psychological science: prevalence, methods for identifying and controlling, and implications for the use of meta-analyses. Psychological Methods 17: 120-128. https://doi.org/10.1037/a0024445.

*Fonner, K.L., and M.E. Roloff. 2010. Why teleworkers are more satisfied with their jobs than are officebased workers: when less contact is beneficial. Journal of Applied Communication Research 38: 336-361. https://doi.org/10.1080/00909882.2010.513998.

Gajendran, R.S., and D.A. Harrison. 2007. The good, the bad, and the unknown about telecommuting: a meta-analysis of psychological mediators and individual consequences. Journal of Applied Psychology 92: 1524-1541. https://doi.org/10.1037/0021-9010.92.6.1524.

*Galanaki, E. 2013. Gender and the importance of fringe benefits: Exploring their link with organizational commitment and job satisfaction, Paper presented at the European Academy of Management Conference, Istanbul, Turkey.

*Gaziel, H.H. 1995. Sabbatical leave, job burnout and turnover intentions among teachers. International Journal of Lifelong Education 14: 331-338. https://doi.org/10.1080/0260137950140406.

*Gehlen, A. 2014. Highway to handsomeness-does the opportunity of sabbaticals influence employer attractiveness? Unpublished master thesis, University of Münster.

*Geldhauser, H. 2007. Income, scheduling flexibility, and diversity policies: An experimental investigation of recruiting older workers, All Theses, Paper 120. http://tigerprints.clemson.edu/all_ theses/120. Accessed 5 Dec 2017.

*Giffords, E.D. 2009. An examination of organizational commitment and professional commitment and the relationship to work environment, demographic and organizational factors. Journal of Social Work 9: 1-19. https://doi.org/10.1177/1468017309346232. 
*Golden, T.D. 2006. Avoiding depletion in virtual work: telework and the intervening impact of work exhaustion on commitment and turnover intentions. Journal of Vocational Behavior 69: 176-187. https://doi.org/10.1016/j.jvb.2006.02.003.

*Golden, T.D., and J.F. Veiga. 2008. The impact of superior-subordinate relationships on the commitment, job satisfaction, and performance of virtual workers. The Leadership Quarterly 19: 77-88. https://doi.org/10.1016/j.leaqua.2007.12.009.

*Golden, T.D., J.F. Veiga, and R.N. Dino. 2008. The impact of professional isolation on teleworker job performance and turnover intentions: does time spent teleworking, interacting face-to-face, or having access to communication-enhancing technology matter? Journal of Applied Psychology 93 : 1412-1421. https://doi.org/10.1037/a0012722.

*Golden, T.D., J.F. Veiga, and Z. Simsek. 2006. Telecommuting's differential impact on work-family conflict: is there no place like home? Journal of Applied Psychology 91: 1340-1350. https://doi.org/ 10.1037/0021-9010.91.6.1340.

Gotsi, M., and A.M. Wilson. 2001. Corporate reputation: seeking a definition. Corporate Communications: An International Journal 6: 24-30. https://doi.org/10.1108/13563280110381189.

Grandey, A.A., and R. Cropanzano. 1999. The conservation of resources model applied to work-family conflict and strain. Journal of Vocational Behavior 54: 350-370. https://doi.org/10.1006/jvbe.1998. 1666.

Grawitch, M.J., P.W. Maloney, L.K. Barber, and C. Yost. 2011. Moving toward a better understanding of the work and nonwork interface. Industrial and Organizational Psychology 4: 385-388. https://doi. org/10.1111/j.1754-9434.2011.01357.x.

*Grover, S.L., and K.J. Crooker. 1995. Who appreciates family-responsive human resource policies: the impact of family-friendly policies on the organizational attachment of parents and non-parents. Personnel Psychology 48: 271-288. https://doi.org/10.1111/j.1744-6570.1995.tb01757.x.

*Gudmundsson, A., Fowler, J., and Whicker, L. 2006. Work/family balance: HRM policy and practice in Australia, Paper presented at the 20th Annual British Academy of Management Conference, Belfast, UK.

Guimaraes, T., and P. Dallow. 1999. Empirically testing the benefits, problems, and success factors for telecommuting programmes. European Journal of Information Systems 8: 40-54. https://doi.org/10. 1057/palgrave.ejis.3000317.

Guo, S., and M.W. Fraser. 2014. Propensity score analysis: statistical methods and applications. Newbury Park: Sage.

Gurstein, P.C. 2001. Wired to the world, chained to the home: telework in daily life. Vancouver: University of British Columbia Press.

*Haar, J. 2008. Work-family conflict and job outcomes: The moderating effects of flexitime use in a New Zealand organization, New Zealand Journal of Employment Relations, 33, 38-54. http://www. nzjournal.org/NZJER_ISSUE_33(1).pdf. (page 39).

Hall, A.T., M.T. Royle, R.W. Brymer, P.L. Perrewé, G.R. Ferris, and W.A. Hochwarter. 2006. Relationships between felt accountability as a stressor and strain reactions: the neutralizing role of autonomy across two studies. Journal of Occupational Health Psychology 11: 87-99. https://doi.org/ 10.1037/1076-8998.11.1.87.

*Halpern, D.F. 2005. How time-flexible work policies can reduce stress, improve health, and save money. Stress and Health 21: 157-168. https://doi.org/10.1002/smi.1049.

Harpaz, I. 2002. Advantages and disadvantages of telecommuting for the individual, organization and society. International Journal of Productivity and Performance Management 51: 74-80. https://doi. org/10.1108/00438020210418791.

Harrison, D.A., G. Johns, and J.J. Martocchio. 2000. Changes in technology, teamwork, and diversity: new directions for a new century of absenteeism research. In Research in personnel and human resources management, 18, ed. G. Ferris, 43-92. Greenwich: JAI Press.

Hedges, L.V., and I. Olkin. 1985. Statistical methods for meta-analysis. Orlando: Academic Press.

Heijstra, T.M., and G.L. Rafnsdottir. 2010. The Internet and academics' workload and work-family balance. Internet and Higher Education 13: 158-163. https://doi.org/10.1016/j.iheduc.2010.03.004.

Highhouse, S., F. Lievens, and E.F. Sinar. 2003. Measuring attraction to organizations. Educational Psychological Measurement 63: 986-1001. https://doi.org/10.1177/0013164403258403.

*Hill, E.J., M. Ferris, and V. Märtinson. 2003. Does it matter where you work? A comparison of how three work venues (traditional office, virtual office, and home office) influence aspects of work and personal/family life. Journal of Vocational Behavior 63: 220-241. https://doi.org/10.1016/S00018791(03)00042-3. 
Hill, E.J., J.G. Grzywacz, S. Allen, V.L. Blanchard, C. Matz-Costa, S. Shulkin, and M. Catsouphes. 2008. Defining and conceptualizing workplace flexibility. Community, Work and Family 11: 149-163. https://doi.org/10.1080/13668800802024678.

Hobfoll, S.E. 1989. Conservation of resources: a new attempt at conceptualizing stress. American Psychologist 44: 513-524. https://doi.org/10.1037/0003-066X.44.3.513.

Hobfoll, S.E. 2002. Social and psychological resources and adaption. Review of General Psychology 6: 307-324. https://doi.org/10.1037/1089-2680.6.4.307.

*Hornung, S., and J. Glaser. 2009. Home-based telecommuting and quality of life: further evidence on an employee-oriented human resource practice. Psychological Reports 104: 395-402. https://doi.org/ 10.2466/PR0.104.2.395-402.

*Hornung, S., D.M. Rousseau, and J. Glaser. 2008. Creating flexible work arrangements through idiosyncratic deals. Journal of Applied Psychology 93: 655-664. https://doi.org/10.1037/0021-9010. 93.3.655.

Hu, L., and P.M. Bentler. 1999. Cutoff criteria for fit indexes in covariance structure analysis: conventional criteria versus new alternatives. Structural Equation Modeling 6: 1-55. https://doi.org/ $10.1080 / 10705519909540118$.

*Hudgies, K. D. 2001. Reactions to telecommuting during recruitment: A look at gender, need for affiliation, and need for autonomy, unpublished master thesis, University of Georgia.

Hunter, J.E., and F.L. Schmidt. 2004. Methods of meta-analysis: correcting errors and bias in research findings, 2nd ed. Newbury Park: Sage.

*Hyland, M. M., and Prottas, D. J. 2010. Testing relationships of work and home flexibility and permeability with cross-border spillovers, paper presented at the 70th Annual Meeting of the Academy of Management, Montreal, Canada.

Igbaria, M., and T. Guimaraes. 1999. Exploring differences in employee turnover intentions and its determinants among telecommuters and non-telecommuters. Journal of Management Information System 16: 147-164. https://doi.org/10.1080/07421222.1999.11518237.

*Ivanauskaitè, A. 2015. The impact of flexible work arrangements on employee engagement and organizational commitment through the mediating role or work-family enrichment, unpublished master thesis, University of Vilnius.

*Kang, C., M. Kim, and J. Lee. 2010. The effects of a month long sabbatical program on helping professionals of nonprofit human service organizations in South Korea: burnout, general health, organizational commitment, and the sense of well-being. Administration in Social Work 35: $20-45$. https://doi.org/10.1080/03643107.2011.533619.

*Kang, Y. 2013. Is family-friendly policy (FFP) working in the private sector of South Korea?, SpringerPlus, 2, 1-11. http://www.springerplus.com/content/2/1/561. Accessed 5 Dec 2017.

*Kar, S., and K.C. Misra. 2013. Nexus between work life balance practices and employee retention-the mediating effect of a supportive culture. Asian Social Science 9: 63-69. https://doi.org/10.5539/ass. v9n11P63.

*Kattenbach, E., E. Demerouti, and F. Nachreiner. 2010. Flexible working times: effects on employees' exhaustion, work-nonwork conflict and job performance. Career Development International 15: 279-295. https://doi.org/10.1108/13620431011053749.

*Kausel, E.E., and J.E. Slaughter. 2011. Narrow personality traits and organizational attraction: evidence for the complementary hypothesis. Organizational Behavior and Human Decision Processes 114: 3-14. https://doi.org/10.1016/j.obhdp.2010.08.002.

*Kelliher, C., and D. Anderson. 2010. Doing more with less? Flexible working practices and the intensification of work, Human Relations 63: 83-106. https://doi.org/10.1177/0018726709349199.

*Kinnunen, U., and S. Mauno. 1998. Antecedents and outcomes of work-family conflict among employed women and men in Finland. Human Relations 51: 157-177. https://doi.org/10.1177/ 001872679805100203.

Knox, S., and C. Freeman. 2006. Measuring and managing employer brand image in the service industry. Journal of Marketing Management 22: 695-716. https://doi.org/10.1362/026725706778612103.

*Kossek, E.E., B.A. Lautsch, and S.C. Eaton. 2006. Telecommuting, control, and boundary management: correlates of policy use and practice, job control, and work-family effectiveness. Journal of Vocational Behavior 68: 347-367. https://doi.org/10.1016/j.jvb.2005.07.002.

Kossek, E.E., S. Lewis, and L.B. Hammer. 2010. Work-life initiatives and organizational change: overcoming mixed messages to move from the margin to the mainstream. Human Relations 61: 3-19. https://doi.org/10.1177/0018726709352385. 
*Krausz, M., A. Sagie, and Y. Bidermann. 2000. Actual and preferred work schedules and scheduling control as determinants of job-related attitudes. Journal of Vocational Behavior 56: 1-11. https:// doi.org/10.1006/jvbe.1999.1688.

*Kröll, C., and Nüesch, S. 2015. Catch the graduates: The effects of flexible work practices on organizational attractiveness, Paper presented at the Scientific Commission of Human Resources of German Academic Association for Business Research, Graz, Austria.

*Kröll, C., and Nüesch, S. 2016. Flexible work practices and organizational attachment: The mediating role of the organizational Culture, unpublished working paper, University of Münster.

Kurland, N.B., and C.D. Cooper. 2002. Manager control and employee isolation in telecommuting environments. Journal of High Technology Management Research 13: 107-126. https://doi.org/10. 1016/S1047-8310(01)00051-7.

*Lee, T.W., and D.R. Johnson. 1991. The effects of work schedule and employment status on the organizational commitment and job satisfaction of full versus part time employees. Journal of Vocational Behavior 38: 208-224. https://doi.org/10.1016/0001-8791(91)90028-K.

Leslie, L.M., C.F. Manchester, T. Park, and S.A. Mehng. 2012. Flexible work practices: a source of career premiums or penalties. Academy of Management Journal 55: 1407-1428. https://doi.org/10.5465/ amj.2010.0651.

Lipsey, M.W., and D.B. Wilson. 2001. Practical meta-analysis. Thousand Oaks: Sage.

*Lu, L., S.-F. Kao, T.-T. Chang, H.-P. Wu, and C.L. Cooper. 2008. Work/family demands, work flexibility, work/family conflict, and their consequences at work: a national probability sample in Taiwan. International Journal of Stress Management 15: 1-21. https://doi.org/10.1037/1072-5245. 15.1.1.

MacCallum, R.C., M.W. Browne, and H.M. Sugawara. 1996. Power analysis and determination of sample size for covariance structure modeling. Psychological Methods 1: 130-149. https://doi.org/10.1037/ 1082-989X.1.2.130.

*Martinez, P., and C.B. Goméz. 2013. Trading telecommuting flexibility for fewer training opportunities? Management Research: The Journal of the Iberoamerican Academy of Management 11: 235-259. https://doi.org/10.1108/MRJIAM-04-2012-0478.

*Masuda, A.D., S.A.Y. Poelmans, T.D. Allen, P.E. Spector, L.M. Lapierre, C.L. Cooper, N. Abarca, P. Brough, P. Ferreiro, G. Fraile, L. Lu, C.-Q. Lu, O.L. Siu, M.P. O’Driscoll, A.S. Simoni, S. Shima, and I. Moreno-Velazquez. 2012. Flexible work arrangements availability and their relationship with work-to-family conflict, job satisfaction and turnover intentions: a comparison of three country clusters. Applied Psychology: An international Review 61: 1-29. https://doi.org/10.1111/j.14640597.2011.00453.x.

*McNall, L.A., A.D. Masuda, and J.M. Nicklin. 2009. Flexible work arrangements, job satisfaction, and turnover intentions: the mediating role of work-to-family enrichment. The Journal of Psychology 144: 61-81. https://doi.org/10.1080/00223980903356073.

*Mennino, S.F., B.A. Rubin, and A. Brayfield. 2005. Home-to-job and job-to-home spillover: the impact of company policies and workplace culture. The Sociological Quarterly 46: 107-135. https://doi. org/10.1111/j.1533-8525.2005.00006.x.

Meyer, J.P., D.J. Stanley, L. Herscovitch, and L. Topolnytsky. 2002. Affective, continuance, and normative commitment to the organization: a meta-analysis of antecedents, correlates, and consequences. Journal of Vocational Behavior 61: 20-52. https://doi.org/10.1006/jvbe.2001.1842.

Mowday, R.T., R.M. Steers, and L.W. Porter. 1979. The measurement of organizational commitment. Journal of Vocational Behavior 14: 224-247. https://doi.org/10.1016/0001-8791(79)90072-1.

* Mulvaney, M. A. 2011. The role of family-friendly benefits on job self-efficacy and organizational commitment of public park and recreation professionals, Journal of Park and Recreation Administration, 29, 58-79. http://thekeep.eiu.edu/recadmin_fac/4. Accessed 5 Dec 2017.

*Mulvaney, M.A. 2014. Leave programs/time off and work-stress family employee benefits programs, organizational commitment, and self-efficacy among municipal employees. Public Personnel Management 43: 459-489. https://doi.org/10.1177/0091026014529661.

*Munsch, M.A. 2016. Flexible work, flexible penalties: the effect of gender, childcare, and type of request on the flexibility bias. Social Forces 94: 1567-1591. https://doi.org/10.1093/sf/sov122.

*Nadler, J.T., N.L. Cundiff, M.R. Lowery, and S. Jackson. 2010. Perceptions of organizational attractiveness: the differential relationships of various work schedule flexibility programs. Management Research Review 33: 865-876. https://doi.org/10.1108/01409171011070297.

*Ng, T.W., M.M. Butts, R.J. Vandenberg, D.M. DeJoy, and M.G. Wilson. 2006. Effects of management communication, opportunity for learning, and work schedule flexibility on organizational 
commitment. Journal of Vocational Behavior 68: 474-489. https://doi.org/10.1016/j.jvb.2005.10. 004.

Ng, T.W., and D.C. Feldman. 2009. Age, work experience, and the psychological contract. Journal of Organizational Behavior 30: 1053-1075. https://doi.org/10.1002/job.599.

*Nicholas, A., and I. Guzman. 2009. Is teleworking for millennials? Faculty and Staff-articles and papers, Paper 24. https://doi.org/10.1145/1542130.1542168.

*Olson, M.H. 1989. Work at home for computer professionals: current attitudes and future prospects. ACM Transactions on Office Information Systems 7: 317-338. https://doi.org/10.1145/76158.76891.

Orwin, R.G., and J.L. Vevea. 2009. Evaluating Coding Decisions. In The handbook of research synthesis and meta-analysis, ed. H. Cooper, L. Hedges, and J. Valentine, 177-203. New York: The Russell Sage Foundation.

*Parasuraman, S., Y.S. Purohit, and V.M. Godshalk. 1996. Work and family variables, entrepreneurial career success, and psychological well-being. Journal of Vocational Behavior 48: 275-300. https:// doi.org/10.1006/jvbe.1996.0025.

Peterson, R.A., and S.P. Brown. 2005. On the use of beta coefficients in meta-analysis. Journal of Applied Psychology 90: 175-181. https://doi.org/10.1037/0021-9010.90.1.175.

*Pierce, J.L., and J.W. Newstrom. 1982. Employee responses to flexible work schedules: an interorganization, inter-system comparison. Journal of Management 8: 9-25. https://doi.org/10.1177/ 014920638200800101.

*Premeaux, S.F., C.L. Adkins, and K. Mossholder. 2007. Balancing work and family: a field study of multi-dimensional, multi-role work-family conflict. Journal of Organizational Behavior 28: 705-727. https://doi.org/10.1002/job.439.

Core Team, R. 2015. R: a language and environment for statistical computing. Vienna: R Foundation for Statistical Computing.

Raghuram, S., and B. Wiesenfeld. 2004. Work-nonwork conflict and job stress among virtual workers. Human Resource Management 43: 259-277. https://doi.org/10.1002/hrm.20019.

*Rau, B.L., and G.A. Adams. 2005. Attracting retirees to apply: desired organizational characteristics of bridge employment. Journal of Organizational Behavior 26: 649-660. https://doi.org/10.1002/job. 330 .

*Rau, B.L., and M.M. Hyland. 2002. Role conflict and flexible work arrangements: the effects on applicant attraction. Personnel Psychology 55: 111-136. https://doi.org/10.1111/j.1744-6570.2002. tb00105.x.

Raudenbush, S.W. 2009. Analyzing effect sizes: Random-effects models. In The Handbook of Research Synthesis and Meta-Analysis, ed. H. Cooper, L. Hedges, and J. Valentine, 295-315. New York: The Russell Sage Foundation.

Rhoades, L., and R. Eisenberger. 2002. Perceived organizational support: a review of the literature. Journal of Applied Psychology 87: 698-714. https://doi.org/10.1037/0021-9010.87.4.698.

*Roehling, P.V., M.V. Roehling, and P. Moen. 2001. The relationship between work-life policies and practices and employee loyalty: a life course perspective. Journal of Family and Economic Issues 22: 141-170. https://doi.org/10.1023/A:1016630229628.

Rosenthal, R. 1979. File drawer problem and tolerance for null results. Psychological Bulletin 86: 638-641. https://doi.org/10.1037/0033-2909.86.3.638.

*Rothbard, N.P., K.W. Phillips, and T.L. Dumas. 2005. Managing multiple roles: work-family policies and individuals' desires for segmentation. Organization Science 16: 243-258. https://doi.org/10. 1287/orsc. 1050.0124 .

Rynes, S.L., and H.E. Miller. 1983. Recruiter and job influences on candidates for employment. Journal of Applied Psychology 68: 147-154. https://doi.org/10.1037/0021-9010.68.1.147.

*Scandura, T.A., and M. Lankau. 1997. Relationships of gender, family responsibility and flexible work hours to organizational commitment and job satisfaction. Journal of Organizational Behavior 18: 377-391. https://doi.org/10.1002/(SICI)1099.

Shadish, W.R., T.D. Cook, and D.T. Campbell. 2002. Experimental and quasi-experimental designs for generalized causal inference. Boston: Houghton Mifflin.

Shadish, W.R., and R.B. Sweeney. 1991. Mediators and moderators in meta-analysis: there's a reason we don't let dodo birds tell us which psychotherapies should have prizes. Journal of Consulting and Clinical Psychology 59: 883-893. https://doi.org/10.1037/0022-006X.59.6.883.

Society for Human Resource Management. 2015. 2015 Employee benefits: An overview of employee benefits offering in the U.S., Alexandria, SHRM. 
Society for Human Resource Management (2016). 2016 Employee benefits: Looking back at 20 years of employee benefits offerings in the U.S. Alexandria: SHRM.

Society for Human Resource Management. 2017. 2017 Employee benefits: remaining competitive in a challenging talent marketplace. Alexandria: SHRM.

Spector, W.R. 1986. Perceived control by employees: a meta-analysis of studies concerning autonomy and participation at work. Human Relations 39: 1005-1016. https://doi.org/10.1177/ 001872678603901104.

Spence, S. 1973. Job market signalling. The Quarterly Journal of Economics 87: 355-374. https://doi.org/ 10.2307/1882010.

Stajkovic, A.D., D. Lee, and A.J. Nyberg. 2009. Collective efficacy, group potency, and group performance: meta-analyses of their relationships, and test of a mediation model. Journal of Applied Psychology 94: 814-828. https://doi.org/10.1037/a0015659.

Steel, P.D., and J.D. Kammeyer-Mueller. 2002. Comparing meta-analytic moderator estimation techniques under realistic conditions. Journal of Applied Psychology 87: 96-111. https://doi.org/ 10.1037/0021-9010.87.1.96.

Steel, R.P., G.S. Shane, and R.W. Griffeth. 1990. Correcting turnover statistics for comparative analysis. Academy of Management Journal 33: 179-187. https://doi.org/10.2307/256357.

*Teerling, T. 2014. Working without time clock. Consequences of flexible work arrangements, unpublished master thesis, University of Münster.

*Thomas, L.T., and D.C. Ganster. 1995. Impact of family-supportive work variables on work-family conflict and strain: a control perspective. Journal of Applied Psychology 80: 6-15. https://doi.org/10. 1037/0021-9010.80.1.6.

*Thompson, R.J., S.C. Payne, and A.B. Taylor. 2015. Applicant attraction to flexible work arrangements: separating the influence of flextime and flexplace. Journal of Occupational and Organizational Psychology 88: 726-749. https://doi.org/10.1111/joop.12095.

Valentine, J.C., and H. Cooper. 2008. A systematic and transparent approach for assessing the methodological quality of intervention effectiveness research: the study design and implementation assessment device (Study DIAD). Psychological Methods 13: 130-149. https://doi.org/10.1037/ 1082-989X.13.2.130.

Viechtbauer, W., and M.W.L. Cheung. 2010. Outlier and influence diagnostics for meta-analysis. Research Synthesis Methods 1: 112-125. https://doi.org/10.1002/jrsm.11.

Viechtbauer, W. 2010. Conducting meta-analyses in R with the metafor package. Journal of Statistical Software 36: 1-48. https://doi.org/10.18637/jss.v036.i03.

Viswesvaran, C., and D.S. Ones. 1995. Theory testing: combining psychometric meta-analysis and structural equations modeling. Personnel Psychology 48: 865-885. https://doi.org/10.1111/j.17446570.1995.tb01784.x.

*Wulfert, S. 2010. If time does not matter: Flextime and trust-based working time and their relation to job satisfaction, affective organizational commitment, work-home interference and job autonomy, unpublished master thesis, University of Nijmegen.

Zahorski, K.J. 1994. The sabbatical mentor: a practical guide to successful sabbaticals. Bolton: Anker Publishing Company.

\section{Publisher's Note}

Springer Nature remains neutral with regard to jurisdictional claims in published maps and institutionalaffiliations. 